Article

\title{
Antioxidative Peptides from Proteolytic Hydrolysates of False Abalone (Volutharpa ampullacea perryi): Characterization, Identification, and Molecular Docking
}

\author{
Shudong He ${ }^{1,2,3,+}$, Yi Zhang ${ }^{4,+}$, Hanju Sun ${ }^{2,3}$, Ming Du ${ }^{1, *}$, Jianlei Qiu ${ }^{2}$, Mingming Tang ${ }^{2}$, \\ Xianbao Sun ${ }^{2}$ and Beiwei Zhu ${ }^{1, *}$ \\ 1 School of Food Science and Technology, National Engineering Research Center of Seafood, \\ Dalian Polytechnic University, Dalian 116034, Liaoning, China; shudong.he@hfut.edu.cn \\ 2 School of Food and Biological Engineering, Engineering Research Center of Bio-process of Ministry of \\ Education, Hefei University of Technology, Hefei 230009, Anhui, China; sunhanjv@163.com (H.S.); \\ m15798936158@163.com (J.Q.); tangmingming@mail.hfut.edu.cn (M.T.); sunxianbao@hotmail.com (X.S.) \\ 3 Anhui Province Key Laboratory of Functional Compound Seasoning, Anhui Qiangwang Seasoning Food \\ Co., Ltd., Jieshou 236500, Anhui, China \\ 4 Department of Food Science and Agricultural Chemistry, McGill University, \\ Ste-Anne-de-Bellevue, QC H9X 3V9, Canada; yi.zhang10@mail.mcgill.ca \\ * Correspondence: duming@dlpu.edu.cn (M.D.); zhubeiwei@163.com (B.Z.); \\ Tel.: +86-0411-863-32275 (M.D.); +86-0411-863-32275 (B.Z.) \\ + These authors contributed equally to this work.
}

Received: 27 December 2018; Accepted: 9 February 2019; Published: 13 February 2019

check for updates

\begin{abstract}
Antioxidative peptides were produced from false abalone (Volutharpa ampullacea perryi) using enzymatic hydrolysis. Trypsin produced the most bioactive hydrolysates with the highest scavenging $\mathrm{ABTS}^{+}$free radicals compared to pepsin, alcalase, neutrase, and flavourzyme. The response surface methodology studies on trypsin hydrolysis indicated that the hydrolysis temperature, time, and $\mathrm{pH}$ were interacted with each other $(p<0.05)$, and the optimal conditions were hydrolysis at $51.8^{\circ} \mathrm{C}$ for $4.1 \mathrm{~h}, \mathrm{pH} 7.7$ and the maximum predicted hydrolysis degree was $13.18 \%$ and $\mathrm{ABTS}^{+}{ }^{\bullet}$ scavenging activity of $79.42 \%$. The optimized hydrolysate was subjected to ultrafiltration fractionation, and the fraction with $\mathrm{MW}<3 \mathrm{kDa}$ showed the highest $\mathrm{ABTS}^{+\bullet}$ scavenging activity. There were 193 peptide sequences identified from this peptide fraction and 133 of them were successfully docked onto human myeloperoxidase (MPO), an enzyme involved in forming reactive oxidants in vivo. The highest scored peptide, no. 39, consists of DTETGVPT. Its structure and molecular interactions with MPO active site were compared with previously characterized peptide hLF1-11. The interactions between peptide no. 39 and MPO include electrostatic charge, hydrogen bonds, and covalent bonds. The antioxidative peptide produced in this research may exert antioxidant activity in vivo due to its potential inhibition effect on MPO.
\end{abstract}

Keywords: false abalone; antioxidative peptides; $\mathrm{ABTS}^{+\bullet}$ scavenging activity; MPO; docking

\section{Introduction}

Compared with pacific abalone (Haliotis discus), which is a highly valued marine shellfish, the false abalone (Volutharpa ampullacea perryi), another deep-sea snail gastropod, is much cheaper but of similar appearance and nutrition value to that of Haliotis discus [1]. False abalone is abundantly found in the North Pacific, especially some coasts of China and Japan, where it is consumed as food [2]. Its edible parts contain approximately $50 \%$ protein (dry weight) [3], which makes it a potential resource 
for developing bioactive peptides to increase its commercial value. Marine-derived peptides have been well studied to be used as bioactive components in functional foods or nutraceuticals and pharmaceuticals. However, bioactive peptides produced from false abalone are rarely reported.

Enzymatic hydrolysis for producing peptides basically includes hydrolysis at optimal conditions, termination of hydrolysis, filtration, fractionation or purification, and freeze-drying [4]. Proteolytic enzymes, either endogenous or exogenous, are a group of enzymes that cleave peptide bonds in protein matrices to generate peptide mixtures with different sizes, amino acid compositions and sequences, as well as peptide structures [5]. However, since each proteolytic enzyme has a different degree of specificity, the selection of proteolytic enzymes certainly determines the bioactivity of the produced peptides.

Antioxidative peptides have broad health benefits by controlling oxidative stress, which plays a role as a promoter for some chronic diseases, such as diabetes, atherosclerosis, arthritis, and cancer [6]. The antioxidant effect of peptides can result from the scavenging of reactive oxygen species (ROS) and chelating transition metal ions [7]. Although the exact mechanism of the antioxidant activity of peptides has not been clearly understood, various research studies have found that certain composed amino acids and their locations, as well as the configuration of the peptide, are involved in the interaction with radicals. Such interactions can be evaluated using in silico molecular docking of peptides with myeloperoxidase (MPO). MPO is abundantly expressed in neutrophils and participates in innate immune defense by forming reactive oxidants contributing to tissue damage; therefore, MPO is used in drug design and development for high-throughput screening of compounds based on the enzyme inhibition mechanism [8]. For example, Guerra-Vargas et al. used MPO (Protein Data Bank (PDB) ID: 1DNU) as a target to further study the synthesized new phenolic compounds that serve as antioxidants [9]. Van der Does et al. used human MPO (PDB ID: 3F9P) to study the inhibition effect of a novel antimicrobial peptide on MPO activity [10].

The objectives of the present research are: (i) to optimize the production of antioxidative peptides from false abalone using proteolytic hydrolysis; (ii) to characterize their antioxidant activity of peptide fractions by spectroscopic evaluations of the scavenging of $\mathrm{ABTS}^{+} \bullet$ (the diammonium salt of 2,2'-azino-bis(3-ethylbenzothiazoline-6-sulfonic acid)); (iii) to identify the amino acid sequences of the optimized peptides using LC-MS/MS; and (iv) to understand the mechanism via the molecular docking model using MPO.

\section{Results and Discussion}

\subsection{The Selection of Proteolytic Enzymes}

Proteolytic enzymes break down peptide bonds to produce protein hydrolysates, which consist of peptides and amino acids. The commercially used proteolytic enzymes are usually protease cocktails, such as the alcalase, neutrase, and flavourzyme that have low specificity on the amino acids residues; besides, trypsin (EC 3.4.21.4), and pepsin (EC 3.4.23.1) are also widely used and they are highly specific to basic and aromatic amino acids residues, respectively [11]. As mentioned previously, the specificity of enzymes determines the size and the sequence of the peptides, and their antioxidant activity. Figure 1a shows the effect of five proteolytic enzymes on the hydrolysis degree of false abalone hydrolysates. Trypsin produced hydrolysates with the highest hydrolysis degree $(12.38 \pm 0.62 \%)(p<0.01)$, followed by non-specific neutrase $(9.08 \pm 0.50 \%)$, and alcalase $(8.57 \pm 0.13 \%)$. Hydrolysates produced from flavourzyme, which is usually used to produce hydrolysates as flavor compounds, had the lowest hydrolysis degree $(2.63 \pm 0.70 \%)$, which had no significant difference with the pepsin-produced hydrolysates (hydrolysis degree of $3.55 \pm 0.05 \%)(p>0.01)$. Hou et al. reported that trypsin produced Alaska pollock protein hydrolysates with the highest hydrolysis degree compared with nine other proteases due to the substrate specificity on lysine and arginine residues of the trypsin, and that trypsin is usually served in higher activity and purity than other proteases as one kind of serine protease [12]. The effect of the five proteolytic enzymes on the $\mathrm{ABTS}^{+\bullet}$ free radical 
scavenging activity is shown in Figure 1b. Trypsin-produced hydrolysates had the highest $\mathrm{ABTS}^{+} \bullet$ scavenging activity of $77.32 \pm 1.25 \%(p<0.01)$, with the amount of proteins of $1.0 \mathrm{mg} / \mathrm{mL}$, and its IC50 value calculated to be $0.69 \mathrm{mg} / \mathrm{mL}$. Similarly, Mao et al. found that casein hydrolysates prepared with alcalase and trypsin had significantly higher DPPH (2,2-diphenyl-1-picrylhydrazyl) free radical scavenging capacity than those prepared with pepsin and flavourzyme [13].

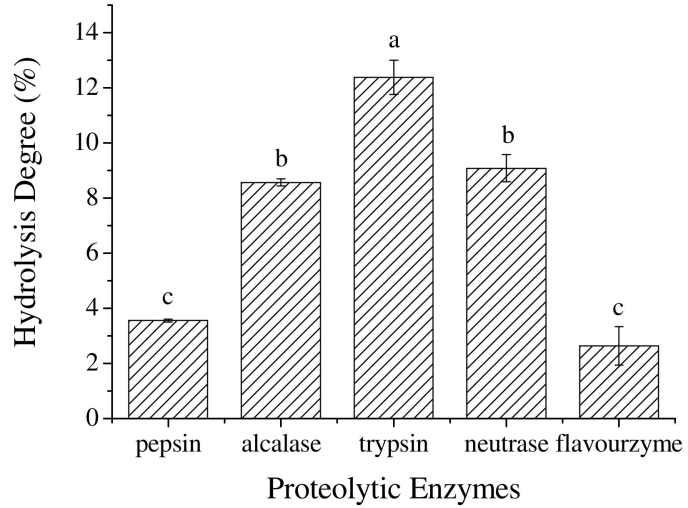

(a)

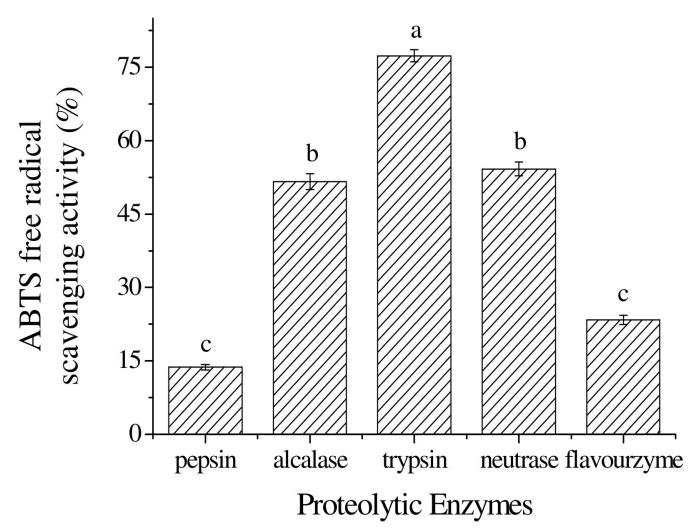

(b)

Figure 1. The effect of proteolytic enzymes on the (a) hydrolysis degree and (b) $\mathrm{ABTS}^{+\bullet}$ free radical scavenging activity of hydrolysates (the amounts of proteins: $1.0 \mathrm{mg} / \mathrm{mL}$ ). Different letters in one panel mean significant difference $(p<0.01)$.

The hydrolysis degree and $\mathrm{ABTS}^{+\bullet}$ scavenging activity of produced hydrolysates followed similar trends, which suggest that the increase of hydrolysis degree may increase the antioxidant properties of hydrolysates to some extent. Higher hydrolysis could result in a larger exposure of the active amino acids residues that are capable of reacting with oxidants [14]. However, extensive hydrolysis could have a negative impact on the functional properties of hydrolysates [15]. Based on the results shown in Figure 1, trypsin was selected to produce oxidative hydrolysates for subsequent optimization studies.

\subsection{Optimum Hydrolysis Conditions}

The hydrolysis degree (Response 1 ) and $\mathrm{ABTS}^{+} \bullet$ free radical scavenging activity (Response 2) are two important indexes of antioxidative hydrolysates produced from enzymes. These two responses obtained under various conditions designed by face-centered central composite design (F-CCCD) are shown in Table 1. It indicated that hydrolysis conditions such as temperature, time, and $\mathrm{pH}$ could influence the hydrolysis and the bioactive property of hydrolysates produced with trypsin.

Table 1. The experiment data for the hydrolysis degree and $\mathrm{ABTS}^{+\bullet}$ scavenging activity of false abalone hydrolysates produced by trypsin using face-centered central composite design (F-CCCD).

\begin{tabular}{|c|c|c|c|c|c|}
\hline \multirow[b]{2}{*}{ Run } & \multicolumn{3}{|c|}{ Independent Variables } & \multicolumn{2}{|c|}{ Responses } \\
\hline & A: Temperature $\left({ }^{\circ} \mathrm{C}\right)$ & B: Time (h) & $\mathrm{C}: \mathrm{pH}$ & $\begin{array}{c}\text { Response 1: } \\
\text { Hydrolysis Degree (\%) }\end{array}$ & $\begin{array}{c}\text { Response } 2: \\
\text { ABTS }^{+\bullet} \text { Scavenging Activity (\%) }\end{array}$ \\
\hline 1 & 50 & 4 & 7 & 12.44 & 77.56 \\
\hline 2 & 50 & 4 & 7 & 12.81 & 77.49 \\
\hline 3 & 40 & 5 & 7 & 6.11 & 65.99 \\
\hline 4 & 50 & 5 & 8 & 10.09 & 77.34 \\
\hline 5 & 50 & 3 & 8 & 9.22 & 74.53 \\
\hline 6 & 50 & 4 & 7 & 12.23 & 77.28 \\
\hline 7 & 60 & 3 & 7 & 6.24 & 69.25 \\
\hline 8 & 50 & 3 & 6 & 3.33 & 66.37 \\
\hline 9 & 40 & 4 & 6 & 4.03 & 62.15 \\
\hline 10 & 60 & 5 & 7 & 5.37 & 72.39 \\
\hline 11 & 60 & 4 & 8 & 10.16 & 75.23 \\
\hline 12 & 50 & 5 & 6 & 4.25 & 66.57 \\
\hline 13 & 50 & 4 & 7 & 12.35 & 77.85 \\
\hline 14 & 60 & 4 & 6 & 5.06 & 64.25 \\
\hline
\end{tabular}


Table 1. Cont.

\begin{tabular}{cccccc}
\hline \multirow{2}{*}{ Run } & \multicolumn{2}{c}{ Independent Variables } & \multicolumn{2}{c}{ Responses } \\
\cline { 2 - 6 } & A: Temperature $\left({ }^{\circ} \mathbf{C}\right)$ & B: Time (h) & C: pH & $\begin{array}{c}\text { Response 1: } \\
\text { Hydrolysis Degree (\%) }\end{array}$ & $\begin{array}{c}\text { Response 2: } \\
\text { ABTS }\end{array}$ - Scavenging Activity (\%) \\
\hline 15 & 50 & 4 & 7 & 12.35 & 77.26 \\
16 & 40 & 3 & 7 & 3.88 & 65.14 \\
17 & 40 & 4 & 8 & 8.67 & 69.25 \\
\hline
\end{tabular}

Response surface analysis data for the hydrolysis degree of hydrolysates (Table 2; Response 1 section) indicated a significant model $(p<0.0001)$, as well as significant $(p<0.05)$ linear effects $\mathrm{A}, \mathrm{B}, \mathrm{C}$; interaction term $\mathrm{AB}$; and quadratic effects $\mathrm{A}^{2}, \mathrm{~B}^{2}, \mathrm{C}^{2}$ for the fitted model, as seen in Equation (1):

$$
\begin{gathered}
\text { Hydrolysis degree }(\%)=12.44+0.52 \mathrm{~A}+0.39 \mathrm{~B}+2.68 \mathrm{C}-3.39 \mathrm{~A}^{2}-3.65 \mathrm{~B}^{2}-2.07 \mathrm{C}^{2}- \\
0.78 \mathrm{AB}+0.12 \mathrm{AC}-0.01 \mathrm{BC} .
\end{gathered}
$$

The lack of fit was not significant $(p=0.1000)$, indicating that the model fitted the data very well. The maximum predicted hydrolysis degree of $13.34 \%$ was obtained according to Equation (1) under the following conditions: temperature $50.82{ }^{\circ} \mathrm{C}$, time $4.04 \mathrm{~h}$, and $\mathrm{pH}$ 7.65. As shown in Figure 2a, hydrolysis temperature (A) and time (B) interacted strongly $(p=0.0027)$ with respect to the hydrolysis degree. The highest hydrolysis degree was observed at hydrolysis temperature of $50{ }^{\circ} \mathrm{C}$ for $4 \mathrm{~h}$. Higher temperature combined with longer hydrolysis time negatively influenced the hydrolysis degree. The reason could be the inactivation effect on trypsin with temperatures above $50^{\circ} \mathrm{C}$, as long treatment time at high temperatures would reduce the availability of the enzyme, increase the concentration of produced peptides that may inhibit the hydrolysis reaction, and decrease the concentration of peptide bonds that limit the reaction speed. Similar observations have been reported for the yellowfin tuna hydrolysates produced using alcalase [16] and $\beta$-lactoglobulin hydrolysates produced using trypsin [17].

$\mathrm{ABTS}^{+} \bullet$ scavenging activity is of prime importance for antioxidative hydrolysates because it is used as a parameter to evaluate the antioxidant properties. As shown in Table 2 (Response 2 section), the corresponding $p<0.0001$ indicated the model fitted well with the experimental data, as expressed in Equation (2):

$$
\begin{gathered}
\text { ABTS }^{+\bullet} \text { scavenging activity }(\%)=77.49+2.32 \mathrm{~A}+0.88 \mathrm{~B}+4.63 \mathrm{C}-6.39 \mathrm{~A}^{2}-2.91 \mathrm{~B}^{2}- \\
3.38 \mathrm{C}^{2}+0.57 \mathrm{AB}+0.97 \mathrm{AC}-0.66 \mathrm{BC} .
\end{gathered}
$$

The $p$ values for all the effects, i.e., linear effects $\mathrm{A}, \mathrm{B}$; interaction terms $\mathrm{AB}, \mathrm{AC}, \mathrm{BC}$; as well as quadratic effects $\mathrm{A}^{2}, \mathrm{~B}^{2}, \mathrm{C}^{2}$ were significant $(p<0.05)$. The lack of fit was not significant $(p=0.0673)$, which confirmed an excellent fitting. The optimum predicted ABTS $^{+\bullet}$ scavenging activity of $79.62 \%$ was obtained, according to Equation (2), under the following conditions: temperature $52.5^{\circ} \mathrm{C}$, time $4.26 \mathrm{~h}$, and $\mathrm{pH} 7.75$. Figure $2 \mathrm{~b}$ shows the significant interaction between hydrolysis temperature (A) and time (B) $(p=0.0270)$. At lower temperatures, the $\mathrm{ABTS}^{+\bullet}$ scavenging activity increased very slowly when hydrolysis time increased. At higher temperatures $\left(>50^{\circ} \mathrm{C}\right)$, as shown in the red surface on the top of the three-dimensional (3D) diagram, the $\mathrm{ABTS}^{+}{ }^{\bullet}$ scavenging activity of hydrolysates increased significantly with the increase of hydrolysis time from 3.5 to $4.5 \mathrm{~h}$. As seen in Figure 2c, the $\mathrm{ABTS}^{+} \bullet$ scavenging activity increased when hydrolysis $\mathrm{pH}$ increased. A higher $\mathrm{pH}$ combined with moderate hydrolysis temperatures favored the production of hydrolysates with high $\mathrm{ABTS}^{+\bullet}$ scavenging activity. Figure $2 \mathrm{~d}$ shows that at higher $\mathrm{pH}$ values $(\mathrm{pH} 7-8)$, the $\mathrm{ABTS}^{+\bullet}$ scavenging activity increased significantly with the increase of hydrolysis time. The hydrolysis $\mathrm{pH}$ had more influence than hydrolysis temperature and time. This might be due to the trypsin used being sensitive to the $\mathrm{pH}$ and active at basic $\mathrm{pH}$ conditions. A previous study found that hydrolysis time, temperature, and enzyme/substrate ratio had interaction effects on the $\mathrm{ABTS}^{+}{ }^{\bullet}$ scavenging activity of fish gelatin hydrolysates prepared using papain [18]. 
Table 2. Statistical summary of the surface response analysis.

\begin{tabular}{lllllll}
\hline \multirow{2}{*}{ Source } & \multicolumn{3}{c}{ Response $\mathbf{c}$} & \multicolumn{2}{c}{ Response 2} \\
\cline { 2 - 7 } & Mean Square & \multicolumn{1}{c}{$\boldsymbol{F}$ Value } & $\boldsymbol{p}$ Value & Mean Square & $\boldsymbol{F}$ Value & $\boldsymbol{p}$ Value \\
\hline Model & 22.13 & 189.74 & $<0.0001$ & 56.43 & 334.76 & $<0.0001$ \\
$\mathrm{~A}$ & 2.14 & 18.37 & 0.0036 & 43.20 & 256.27 & $<0.0001$ \\
$\mathrm{~B}$ & 1.24 & 10.63 & 0.0138 & 6.13 & 36.34 & 0.0005 \\
$\mathrm{C}$ & 57.62 & 493.99 & $<0.0001$ & 171.22 & 1015.74 & $<0.0001$ \\
$\mathrm{AB}$ & 2.40 & 20.60 & 0.0027 & 1.31 & 7.78 & 0.0270 \\
$\mathrm{AC}$ & 0.0529 & 0.4535 & 0.5223 & 3.76 & 22.33 & 0.0021 \\
$\mathrm{BC}$ & 0.0006 & 0.0054 & 0.9437 & 1.70 & 10.10 & 0.0155 \\
$\mathrm{~A}^{2}$ & 48.37 & 414.66 & $<0.0001$ & 171.87 & 1019.61 & $<0.0001$ \\
$\mathrm{~B}^{2}$ & 55.99 & 480.06 & $<0.0001$ & 35.57 & 211.01 & $<0.0001$ \\
$\mathrm{C}^{2}$ & 17.99 & 154.19 & $<0.0001$ & 48.07 & 285.20 & $<0.0001$ \\
Residual & 0.1166 & & & 0.1686 & & 0.0673 \\
Lack of fit & 0.2065 & 4.19 & 0.1000 & 0.3162 & 5.46 & \\
Pure error & 0.0493 & & & 0.0579 & &
\end{tabular}

A is hydrolysis temperature, B is hydrolysis time, and C is hydrolysis $\mathrm{pH}$. Response $1: R^{2}=0.9959$, Adj $R^{2}=0.9907$, Pred $R^{2}=0.9489$, Adeq Precision $=33.6087$. Response $2: R^{2}=0.9977$, Adj $R^{2}=0.9947$, Pred $R^{2}=0.9695$, Adeq Precision $=50.0111$.

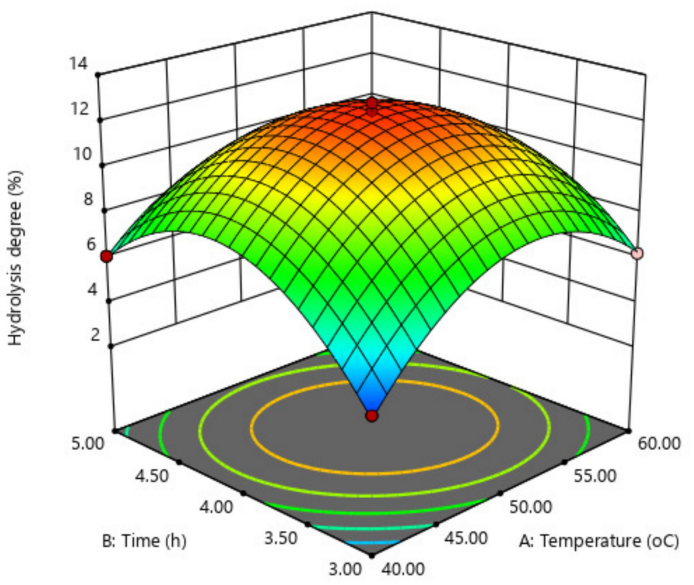

(a)

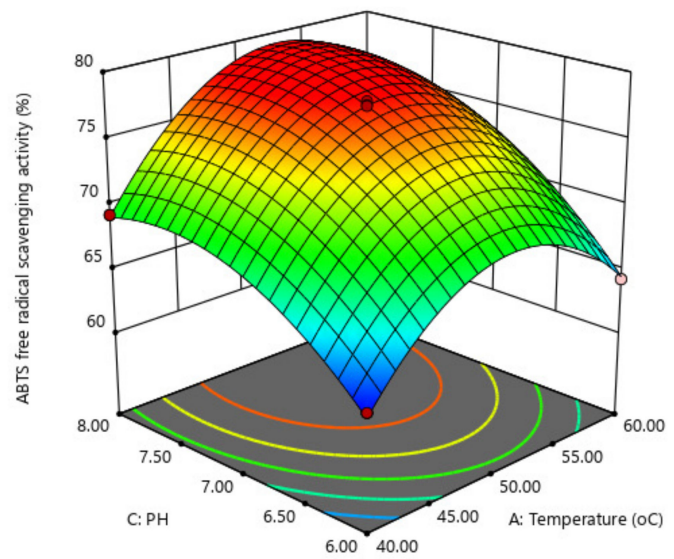

(c)

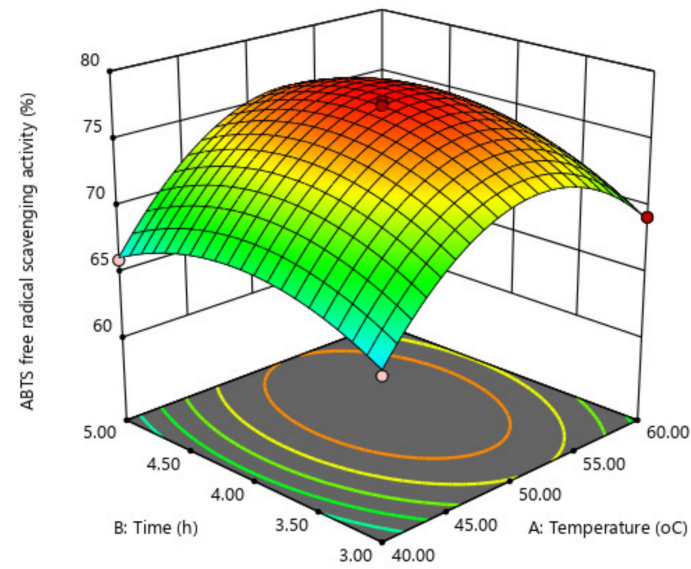

(b)

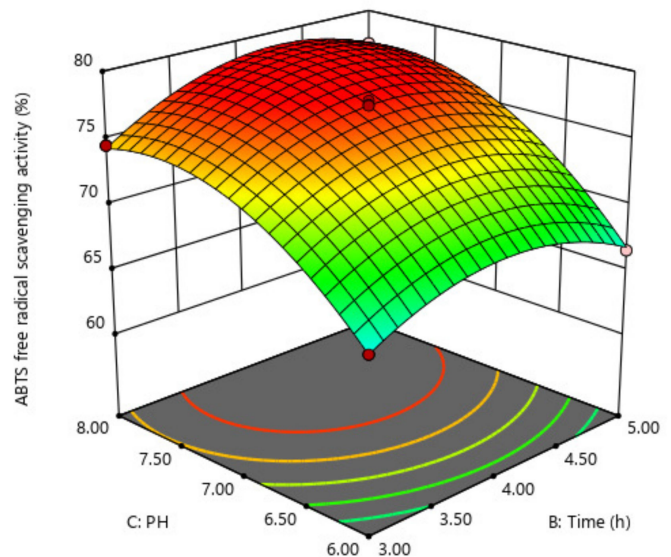

(d)

Figure 2. Three-dimensional (3D) response surface plots. (a) Hydrolysis degree (\%) as a function of temperature $\left({ }^{\circ} \mathrm{C}\right) \times$ time $(\mathrm{h}) ;(\mathbf{b}) \mathrm{ABTS}^{+\bullet}$ scavenging activity $(\%)$ as a function of temperature $\left({ }^{\circ} \mathrm{C}\right)$ $\times$ time (h); (c) $\mathrm{ABTS}^{+\bullet}$ scavenging activity $(\%)$ as a function of temperature $\left({ }^{\circ} \mathrm{C}\right) \times \mathrm{pH}$; (d) $\mathrm{ABTS}^{+\bullet}$ scavenging activity $(\%)$ as a function of time $(\mathrm{h}) \times \mathrm{pH}$. 
Then, with respect to both hydrolysis degree and antioxidative activity, the first partial derivatives of the regression models were applied to optimize the enzymatic hydrolysis by combining the Equations (1) and (2). Hence, the optimum conditions of hydrolysis temperature at $51.81{ }^{\circ} \mathrm{C}$ for $4.13 \mathrm{~h}$ at $\mathrm{pH} 7.7$ were determined to produce antioxidative hydrolysates using trypsin, and the maximum predicted hydrolysis degree was $13.27 \%$ with $\mathrm{ABTS}^{+\bullet}$ scavenging activity of $79.54 \%$. To verify the model, the practical conditions of hydrolysis temperature at $51.8^{\circ} \mathrm{C}$ for $4.1 \mathrm{~h}$ at $\mathrm{pH} 7.7$ were applied because of the control accuracy of the equipment. New hydrolysates produced under these conditions showed a hydrolysis degree of $13.18 \pm 0.31 \%$ and ABTS $^{+}$scavenging activity of $79.42 \pm 0.33 \%$, which showed no significant difference from the predicted data $(p>0.05)$. The optimized hydrolysates were subjected to fractionation using ultrafiltration to determine the effect of fraction MW on their anti-oxidant properties.

\subsection{The Effect of $M W$}

The molecular weight of protein hydrolysates that resulted from the enzymatic hydrolysis degree was highly related with their bioactivity. After the ultrafiltration, all the protein hydrolysates were diluted. Then the protein concentration of any fraction was adjusted to $0.1 \mathrm{mg} / \mathrm{mL}$ prior to the determination of antioxidant properties. As seen in Figure 3, the ABTS ${ }^{+}$scavenging activity of hydrolysate fractions increased significantly from MW of $<10 \mathrm{kDa}$ to MW of $5-10 \mathrm{kDa}(p<0.01)$, and the increase of activity between hydrolysate fraction 3-5 kDa and $<3 \mathrm{kDa}$ was gradual. The hydrolysate fraction with a MW $<3 \mathrm{kDa}$ was found to have the highest $\mathrm{ABTS}^{+} \bullet$ scavenging activity of $55.37 \pm 1.33 \%$ $(p<0.01)$ at a low protein concentration of $0.1 \mathrm{mg} / \mathrm{mL}$. Since the IC50 value of the $<3 \mathrm{kDa}$ hydrolysate fraction was calculated to be $0.09 \mathrm{mg} / \mathrm{mL}$, which was about 7.7 times higher than that of the initial tryptic hydrolysate, the results indicated that the lower the MW of the hydrolysates, the higher the $\mathrm{ABTS}^{+}$scavenging activity. Protein hydrolysates from fish, beans, milk, etc., with a MW range of 0-3 kDa, have been reported with higher antioxidant properties [19-21]. Besides, peptides with lower MW are easier to cross the intestinal barrier and exert the antioxidant effect and can interact more effectively with free radicals [22], which favor their usage as pharmaceuticals.

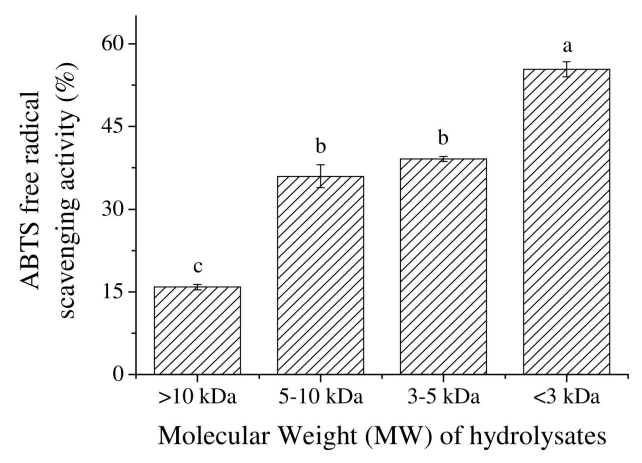

Figure 3. The effect of fractions with different MW from optimized hydrolysates on the ABTS ${ }^{+\bullet}$ scavenging activity.

\subsection{Identification of Peptide Sequences by LC-MS/MS}

The fraction with MW of $<3 \mathrm{kDa}$ was loaded onto LC-MS/MS to characterize their sequences of the composed amino acids. There were 193 peptides recognized in the hydrolysate fraction, as listed in Supplementary Table S1. Results showed that all peptide sequences were made of 6-26 amino acids residues. Previous research has found that bioactive peptides usually contain 2-20 amino acid residues $[23,24]$. In the current study, the molecular mass of the peptide sequences ranged from 699 to $2560 \mathrm{Da}$, which also confirmed the effective fractionation using ultrafiltration to produce peptides with MW $<3 \mathrm{kDa}$. 
The peptide sequences in the MW $<3 \mathrm{kDa}$ had various amino acid residues at their $\mathrm{N}$ - or C-terminals. Trypsin could specifically cleave the C-terminal to arginine $(\mathrm{R})$ or lysine $(\mathrm{K})$ residues. There were 81 peptide sequences ( $42 \%$ of the total peptide sequences) with $\mathrm{R}$ or $\mathrm{K}$ residues on the C-terminal, which implied the efficiency of enzymatic hydrolysis using trypsin. It has been reported that trypsin-generated peptides from royal jelly protein hydrolysates had high antioxidant and antimicrobial activities $[25,26]$. The presence of peptide sequences with other residues on the C-terminal may have been caused by the impurity of trypsin enzymes, or autohydrolysis may have occurred with the endogenous digestive enzymes from false abalone, or the breakdown of random peptide bonds at heating treatment (i.e., $51.8^{\circ} \mathrm{C}$ for $4.1 \mathrm{~h}$ ), or the matching degree of the MS/MS database. The diversity of the remaining residues on the peptide sequence terminals contributed to the antioxidant properties. For instance, proline $(\mathrm{P})$ residues at both terminals were found in peptides that had both antioxidant and $\alpha$-amylase inhibitory activities [24]; the presence of the $\mathrm{N}$-terminal histidine (H) was shown to exert antioxidant protection [27].

Previous research studies have found that antioxidative peptides usually contain hydrophobic amino acids, such as glycine $(\mathrm{G})$, alanine $(\mathrm{A})$, valine $(\mathrm{V})$, leucine $(\mathrm{L})$, isoleucine $(\mathrm{I})$, proline $(\mathrm{P})$, phenylalanine $(\mathrm{F})$, methionine $(\mathrm{M})$, and tryptophan $(\mathrm{W})$ [28]. Those residues were found in almost all the 193 characterized peptide sequences, suggesting that they could enhance the presence of peptides in the water-lipid interaction phase to facilitate the scavenging of free radicals according to the previous study [29]. Among these hydrophobic amino acids, leucine (L) was found in the majority of the characterized peptides. This was in agreement with research on peptides from buffalo and bovine casein hydrolysates with high antioxidant properties [30]. It might be due to the long aliphatic side chain from leucine residues that contributed to the interaction with the acyl chains of fatty acids [31]. Besides, amino acid residues, such as histidine (H), and cysteine (C) are also found in the peptides sequences, which have been reported with relation to radical scavenging activity due to their special characteristics, such as the imidazole group in histidine and the sulfur hydrogen donated by cysteine [32].

\subsection{Molecular Mechanism}

There were 133 among 193 identified peptide sequences successfully being docked with the MPO enzyme, which suggested that $69 \%$ of peptides in the false abalone hydrolysate with $\mathrm{MW}<3 \mathrm{kDa}$ had potential antioxidant activity in vivo. These 133 peptide sequences had a total of 820 docking poses (data not shown), and based on the "score ligand poses" function with calculations from LigScore1, LigScore2, PLP1, PLP2, Jain, PMF, PMF04, and CDOCKER scores algorithms, 107 best poses from 107 peptides were returned and listed in Table 3, which were ordered by the consensus scores based on the scores that had been previously computed. Peptide no. 39 with 8 amino acid residues Asp-Thr-Glu-Thr-Gly-Val-Pro-Thr (DTETGVPT) had the best consensus score. There were another 39 peptide sequences in number had consensus scores of 2 , and the amounts of peptides with consensus scores of 1 and 0 were 53 and 14, respectively. The reference bioactive peptide hLF1-11, made up of 11 amino acid residues (Gly-Arg-Arg-Arg-Arg-Ser-Val-Gln-Trp-Cys-Ala, GRRRRSVQWCA), has been characterized in structure [10,33]. The docking study of this hLF1-11 with MPO showed that several electrostatic interactions were involved so that hLF1-11 could occupy the active site of MPO and block its catalytic activity [10]. In this study, we used hLF1-11 to compare with the docked peptides, especially peptide no. 39, using the docking procedure described in Section 3.9, to help to illustrate the molecular mechanism of peptide no. 39 for its antioxidant effect. 
Table 3. The energy and the amino acid residues involved in the interactions between peptides and myeloperoxidase (MPO) from the molecular docking study.

\begin{tabular}{|c|c|c|c|c|c|c|c|}
\hline Peptide no. & Peptide Sequence & Consensus Score & $\begin{array}{c}\text {-CDOCKER } \\
\text { Interaction Energy }\end{array}$ & $\begin{array}{l}\text { Interactions with A Chain } \\
\text { of MPO }\end{array}$ & $\begin{array}{l}\text { Interactions with B Chain } \\
\text { of MPO }\end{array}$ & $\begin{array}{l}\text { Interactions with C Chain } \\
\text { of MPO }\end{array}$ & $\begin{array}{c}\text { Interactions with D Chain } \\
\text { of MPO }\end{array}$ \\
\hline hLF1-11 & GRRRRSVQWCA & - & 120.282 & ARG31, LEU33, PRO34 & VAL30, ARG31, TRP32 & $\begin{array}{l}\text { THR159, ASN162, ARG323, } \\
\text { LYS505 }\end{array}$ & $\begin{array}{l}\text { ALA152, CYS153, ILE160, } \\
\text { ASN162, PHE439, LYS505 }\end{array}$ \\
\hline 39 & DTETGVPT & 3 & 121.516 & AGR31, TRP32 & $\begin{array}{l}\text { ALA28, PHE29. VAL30, } \\
\text { ARG31, TRP32 }\end{array}$ & ILE160, ARG323, LYS505 & $\begin{array}{l}\text { ALA152, CYS153, THR159, } \\
\text { ILE160, ARG323, LYS505 }\end{array}$ \\
\hline 1 & NDNIQR & 2 & 96.9148 & ARG31, PRO34 & ARG31, TRP32, ALA35 & ILE160, LYS505 & $\begin{array}{l}\text { ILE160, ASN162, ARG323, } \\
\text { LYS505 }\end{array}$ \\
\hline 2 & IELLLL & 2 & 112.572 & ARG31, TRP32, PRO34 & $\begin{array}{l}\text { ALA28, ARG31, PRO34, } \\
\text { ALA35 }\end{array}$ & ILE160, ASN162, PHE439 & $\begin{array}{l}\text { ALA152, CYS153, THR159, } \\
\text { ILE160, ASN162, ARG323 }\end{array}$ \\
\hline 4 & LADEIR & 2 & 101.61 & ARG31, TRP32, PRO34 & VAL30, ARG31, TRP32 & ILE160, ASN162, LYS505 & ALA152, CYS153, ARG323 \\
\hline 5 & LLKDQL & 2 & 106.002 & $\begin{array}{l}\text { ALA28, VAL30, ARG31, } \\
\text { PRO34 }\end{array}$ & ALA28, TRP32 & ILE160, ARG323, LYS505 & ARG323, LYS505 \\
\hline 6 & LEILNT & 2 & 95.5421 & VAL30, ARG31 & ALA28, ARG31 & $\begin{array}{l}\text { ALA152, CYS153, ILE160, } \\
\text { ASN162, ARG323, LYS505 }\end{array}$ & $\begin{array}{c}\text { THR159, ILE160, ASN162, } \\
\text { ARG323 }\end{array}$ \\
\hline 8 & QDPLNR & 2 & 105.976 & $\begin{array}{c}\text { PHE29, ARG31, TRP32, } \\
\text { PRO34, ALA35 }\end{array}$ & TRP32 & ILE160, ASN162 & ASP321, ARG323, LYS505 \\
\hline 9 & QVQNVR & 2 & 94.6778 & ARG31, PRO34 & ARG31, TRP32, PRO34 & ILE160, ASN162, ARG323 & $\begin{array}{l}\text { ILE160, ASN162, SER319, } \\
\text { ARG323, LYS505 }\end{array}$ \\
\hline 10 & GTELFR & 2 & 97.3112 & ARG31, TRP32, PRO34 & ARG31, TRP32, ALA35 & ASN162, ARG323, LYS505 & $\begin{array}{l}\text { ILE160, ASN162, ARG323, } \\
\text { LYS505 }\end{array}$ \\
\hline 12 & ISAAELR & 2 & 99.0441 & ARG31, TRP32, ALA35 & ARG31 & ILE160, ARG323, LYS505 & ILE160, ASN162, ARG323 \\
\hline 13 & FPSIVGR & 2 & 89.5673 & VAL30, ARG31 & $\begin{array}{l}\text { ALA28, PHE29, VAL30, } \\
\text { ARG31, PRO34, ALA335 }\end{array}$ & $\begin{array}{l}\text { ILE160, ASN162, SER319, } \\
\text { ARG323, LYS505 }\end{array}$ & ALA152, CYS153, ILE160 \\
\hline 14 & LTGMAFR & 2 & 90.0454 & ARG31, LEU33 & ARG31, TRP32, PRO34 & ILE160, ARG323 & $\begin{array}{l}\text { ILE160, ASN162, ARG323, } \\
\text { LYS505 }\end{array}$ \\
\hline 16 & FAPQLLT & 2 & 105.345 & ALA28, ARG31 & $\begin{array}{l}\text { ALA28, PHE29, VAL30, } \\
\text { ARG31, PRO34 }\end{array}$ & ILE160, ARG323 & ILE160, ASN162, ARG323 \\
\hline 20 & LEVNLMT & 2 & 106.656 & $\begin{array}{l}\text { PHE29, ARG31, TRP32, } \\
\text { PRO34 }\end{array}$ & $\begin{array}{l}\text { ALA28, ARG31, TRP32, } \\
\text { LEU33 }\end{array}$ & $\begin{array}{l}\text { ILE160, ASN162, ARG323, } \\
\text { LYS505 }\end{array}$ & $\begin{array}{l}\text { ALA152, ILE160, ASN162, } \\
\text { ARG323 }\end{array}$ \\
\hline 22 & HLQLAIR & 2 & 98.3054 & ALA28, ARG31, TRP32 & ARG31, TRP32 & THR159, ILE160, ARG323 & $\begin{array}{l}\text { SER156, THR159, ILE160, } \\
\text { ASP321, ARG323 }\end{array}$ \\
\hline 23 & IAKEGFA & 2 & 92.2588 & $\begin{array}{l}\text { PHE29, ARG31, LEU33, } \\
\text { PRO34 }\end{array}$ & ARG31, TRP32 & THR159, ARG323, LYS505 & ILE160, ASN162 \\
\hline 24 & NLNPTTK & 2 & 95.8118 & ARG31, TRP32, PRO34 & PHE29, ARG31, ALA35 & CYS153, ARG323 & ILE160, ASN162, ARG323 \\
\hline 25 & VSHYSTK & 2 & 90.9066 & ARG31 & $\begin{array}{l}\text { ALA28, ARG31, TRP32, } \\
\text { ALA35 }\end{array}$ & ILE160, ASN162, ARG323 & ALA152, IEL160, ARG323 \\
\hline 28 & GLLLHWS & 2 & 99.7525 & $\begin{array}{l}\text { ALA28, VAL30, ARG31, } \\
\text { TRP32 }\end{array}$ & $\begin{array}{l}\text { ALA28, PHE29, ARG31, } \\
\text { TRP32, PRO34 }\end{array}$ & $\begin{array}{l}\text { ALA152, CYS153, ILE160, } \\
\text { ARG323, LYS505 }\end{array}$ & $\begin{array}{l}\text { ILE160, ASN162, ARG323, } \\
\text { LYS505 }\end{array}$ \\
\hline 29 & LQLISAG & 2 & 89.9116 & ALA28, ARG31, TRP32 & VAL30, ARG31 & $\begin{array}{l}\text { CYS153, ILE160, ARG161, } \\
\text { ASN162, ASP321, ARG323, } \\
\text { LYS505 }\end{array}$ & ILE160, ASN162 \\
\hline 30 & QCELNFK & 2 & 103.547 & ARG31, PRO34 & - & $\begin{array}{l}\text { ILE160, ASN162, ARG323, } \\
\text { LYS505 }\end{array}$ & $\begin{array}{l}\text { ALA152, CYS153, ASN162, } \\
\text { ARG323 }\end{array}$ \\
\hline
\end{tabular}


Table 3. Cont

\begin{tabular}{|c|c|c|c|c|c|c|c|}
\hline Peptide no. & Peptide Sequence & Consensus Score & $\begin{array}{c}\text {-CDOCKER } \\
\text { Interaction Energy }\end{array}$ & $\begin{array}{c}\text { Interactions with A Chain } \\
\text { of MPO }\end{array}$ & $\begin{array}{l}\text { Interactions with B Chain } \\
\text { of MPO }\end{array}$ & $\begin{array}{c}\text { Interactions with C Chain } \\
\text { of MPO }\end{array}$ & $\begin{array}{c}\text { Interactions with D Chain } \\
\text { of MPO }\end{array}$ \\
\hline 31 & GIHETTY & 2 & 120.866 & VAL30, ARG31, PRO34 & $\begin{array}{l}\text { ALA28, ARG31, TRP32, } \\
\text { PRO34 }\end{array}$ & $\begin{array}{l}\text { THR159, ILE160, ASN162, } \\
\text { ARG323 }\end{array}$ & ALA152, ILE160, ARG323 \\
\hline 45 & VASFSTHK & 2 & 97.4559 & ALA28, ARG31 & $\begin{array}{l}\text { ALA28, VAL30, ARG31, } \\
\text { TRP32 }\end{array}$ & ILE160 & $\begin{array}{l}\text { ALA152, SER319, ARG323, } \\
\text { LYS505 }\end{array}$ \\
\hline 46 & AVAGLGIL & 2 & 94.3888 & ARG31, TRP32 & PHE29, ARG31, TRP32 & $\begin{array}{l}\text { ALA152, CYS153, ILE160, } \\
\text { ASN162, ARG323, LYS505 }\end{array}$ & $\begin{array}{c}\text { CYS153, ILE160, ASN162, } \\
\text { ARG323 }\end{array}$ \\
\hline 48 & VGDEAQSK & 2 & 114.397 & ARG31 & ALA28, TRP32 & YHR159, ILE160, ARG323 & $\begin{array}{c}\text { THR159, ILE160, ASN162, } \\
\text { ARG323, LYS505 }\end{array}$ \\
\hline 49 & SSSVVAAL & 2 & 95.2041 & ARG31 & ARG31, TRP32 & ASN162, ARG323, LYS505 & $\begin{array}{l}\text { ALA152, CYS153, ASN162, } \\
\text { ARG323 }\end{array}$ \\
\hline 50 & FAGDDAPR & 2 & 113.395 & ARG31, TRP32, PRO34 & $\begin{array}{l}\text { PHE29, VAL30, ARG31, } \\
\text { TRP32, PRO34 }\end{array}$ & ILE160, ASN162, ARG323 & $\begin{array}{l}\text { THR159, ILE160, ASN162, } \\
\text { ARG323 }\end{array}$ \\
\hline 55 & KTKDDMHL & 2 & 111.666 & $\begin{array}{l}\text { ARG31, TRP32, PRO34, } \\
\text { ALA35 }\end{array}$ & ARG31, TRP32, PRO34 & ILE160, ARG323, LYS505 & $\begin{array}{l}\text { CYS153, THR159, ILE160, } \\
\text { ARG323 }\end{array}$ \\
\hline 58 & VIPELNGK & 2 & 108.917 & ALA28, ARG31 & ALA28, ARG31, ALA35 & ARG323, LYS505 & ILE160, ASN163, ARG323 \\
\hline 62 & GFAGDDAPR & 2 & 128.195 & $\begin{array}{l}\text { ALA28, ARG31, TRP32, } \\
\text { ALA35 }\end{array}$ & ALA28, ARG31, TRP32 & $\begin{array}{l}\text { ILE160, SER319, ARG323, } \\
\text { LYS505 }\end{array}$ & ILE160, ASN162, ARG323 \\
\hline 64 & VATVGPISV & 2 & 96.6785 & ALA28, ARG31, PRO34 & $\begin{array}{l}\text { ALA28, VAL30, ARG31, } \\
\text { TRP32, PRO34 }\end{array}$ & THR159, ILE160, ARG323 & $\begin{array}{l}\text { ILE160, ASN162, ARG323, } \\
\text { LYS505 }\end{array}$ \\
\hline 68 & SSSVALHKH & 2 & 78.6093 & ARG31, TRP32, PRO34 & ARG31, TRP32 & $\begin{array}{l}\text { PRO151, CYS153, THR159, } \\
\text { ILE160, ARG161, ASN162, } \\
\text { ARG323, LYS505 }\end{array}$ & THR159, ILE160, ARG323 \\
\hline 71 & GGKNLDELE & 2 & 145.154 & ARG31, PRO34 & $\begin{array}{l}\text { ALA28, PHE29, ARG31, } \\
\text { TRP32 }\end{array}$ & ILE160, ARG323 & $\begin{array}{c}\text { CYS153, SER156, THR159, } \\
\text { ILE160, ASN162, ASP321, } \\
\text { ARG323, LYS505 }\end{array}$ \\
\hline 111 & VGSSFVGGFG & 2 & 103.741 & VAL30, ARG31, TRP32 & ALA28, ARG31 & ILE160, ASN162, LYS505 & $\begin{array}{l}\text { PRO151, CYS153, SER156, } \\
\text { THR159, ILE160, ARG161, } \\
\text { ASN162, ARG323 }\end{array}$ \\
\hline 112 & DVNSLKSALA & 2 & 103.755 & ARG31, TRP32 & VAL30, ARG31, TRP32 & $\begin{array}{l}\text { CYS153, ILE160, ARG323, } \\
\text { LYS505 }\end{array}$ & $\begin{array}{l}\text { ALA152, CYS153, ILE160, } \\
\text { ARG161, ASN162 }\end{array}$ \\
\hline 118 & IGGIGTVPVGR & 2 & 106.314 & ARG31, PRO34, SER42 & $\begin{array}{l}\text { VAL30, ARG31, TRP32, } \\
\text { PRO34 }\end{array}$ & $\begin{array}{c}\text { PRO151, ALA152, CYS153, } \\
\text { SER156, ILE160, ASN162, } \\
\text { ASN317, SER319 } \\
\end{array}$ & ARG323, ARG438, PHE439 \\
\hline 125 & AGLFVSSFFSV & 2 & 116.238 & ALA28, ARG31, TRP32 & $\begin{array}{l}\text { ALA28, VAL30, ARG31, } \\
\text { PHE41 }\end{array}$ & $\begin{array}{l}\text { CYS153, LYS308, ASP321, } \\
\text { ARG323, PHE439, LYS505 }\end{array}$ & $\begin{array}{c}\text { CYS153, SER156, THR159, } \\
\text { ILE160, ARG323 }\end{array}$ \\
\hline 148 & LTASGPSIGARP & 2 & 122.053 & ARG31 & ALA28, TRP32, ASP39 & ARG323, LYS505, PHE439 & $\begin{array}{l}\text { PRO123, ALA152, CYS153, } \\
\text { GLY155, SER156, THR159, } \\
\text { ILE160, ARG161, ASN162 }\end{array}$ \\
\hline 182 & ILVGAAVCFFCLILA & 2 & 116.4 & ALA28, PRO103 & ARG31, TRP32 & $\begin{array}{l}\text { PRO151, CYS153, PRO154, } \\
\text { GLY155, SER156, THR159, } \\
\text { ILE160, ARG161, ASN162, } \\
\text { ARG323 }\end{array}$ & $\begin{array}{l}\text { ILE160, ASN162, LYS308, } \\
\text { ASP321, ARG323, PHE439, } \\
\text { LYS505 }\end{array}$ \\
\hline
\end{tabular}


Table 3. Cont

\begin{tabular}{|c|c|c|c|c|c|c|c|}
\hline Peptide no. & Peptide Sequence & Consensus Score & $\begin{array}{c}\text {-CDOCKER } \\
\text { Interaction Energy }\end{array}$ & $\begin{array}{l}\text { Interactions with A Chain } \\
\text { of MPO }\end{array}$ & $\begin{array}{l}\text { Interactions with B Chain } \\
\text { of MPO }\end{array}$ & $\begin{array}{c}\text { Interactions with C Chain } \\
\text { of MPO }\end{array}$ & $\begin{array}{c}\text { Interactions with D Chain } \\
\text { of MPO }\end{array}$ \\
\hline 183 & STAGDTHLGGEDFDNR & 2 & 140.863 & ALA28, TRP32 & $\begin{array}{l}\text { ARG31, PRG41, SER42, } \\
\text { LEU43 }\end{array}$ & $\begin{array}{l}\text { LYS308, ASP321, ARG323, } \\
\text { PHE439, CYS440, CYS497, } \\
\text { CYS505, LYS505 }\end{array}$ & $\begin{array}{c}\text { PRO151, CYS153, GLY155, } \\
\text { THR159, ILE160, ARG161, } \\
\text { ASN162, ARG323 }\end{array}$ \\
\hline 7 & NWDLVG & 1 & 99.433 & PHE29, VAL30, ARG31 & $\begin{array}{l}\text { ALA28, PHE29, VAL30, } \\
\text { ARG31, TRP32 }\end{array}$ & ARG323 & ARG323 \\
\hline 11 & LLVKLL & 1 & 86.1708 & $\begin{array}{l}\text { ALA28, VAL30, ARG31, } \\
\text { TRP32, PRO34 }\end{array}$ & $\begin{array}{l}\text { PHE29, VAL30, ARG31, } \\
\text { PRO34 }\end{array}$ & $\begin{array}{l}\text { ALA152, CYS153, ASN162, } \\
\text { ARG323, LYS505 }\end{array}$ & ILE160, ASN162 \\
\hline 15 & FPGIADR & 1 & 88.1065 & VAL30, ARG31 & $\begin{array}{l}\text { PHE29, VAL30, ARG31, } \\
\text { TRP32, }\end{array}$ & ASN162, ARG323 & ILE160, SER319, ARG323 \\
\hline 17 & IIAPPER & 1 & 96.3472 & $\begin{array}{l}\text { VAL30, ARG31, TRP32, } \\
\text { PRO34 }\end{array}$ & ALA28, ARG31, TRP32 & $\begin{array}{l}\text { ALA152, CYS153, IEL160, } \\
\text { ASN162, ARG323, LYS505 }\end{array}$ & ILE160, ARG323, LYS505 \\
\hline 21 & LIILELL & 1 & 98.6814 & $\begin{array}{l}\text { ALA28, ARG31, TRP32, } \\
\text { LEU33, PRO34 }\end{array}$ & $\begin{array}{l}\text { ALA28, VAL30, ARG31, } \\
\text { PRO34 }\end{array}$ & ILE160, ARG323, LYS505 & $\begin{array}{l}\text { ALA152, CYS153, ILE160, } \\
\text { ASN162 }\end{array}$ \\
\hline 26 & NLLNIPK & 1 & 86.0812 & VAL30, ARG31, PRO34 & ARG31, TRP32, PRO34 & ILE160, ARG323 & THR159, ILE160 \\
\hline 27 & SFRENNT & 1 & 102.146 & ARG31, PRO34 & PHE29, ARG31, TRP32 & ILE160, ASN162, LYS505 & $\begin{array}{l}\text { ASN162, ASP321, ARG323, } \\
\text { LYS505 }\end{array}$ \\
\hline 32 & TEAPLNPK & 1 & 101.636 & $\begin{array}{l}\text { VAL30, ARG31, TRP32, } \\
\text { PRO34 } \\
\end{array}$ & ALA28, ARG31, PRO34 & $\begin{array}{l}\text { THR159, ILE160, ASN162, } \\
\text { LYS505 }\end{array}$ & ILE160, ASN162, ARG323 \\
\hline 34 & IILLLLV & 1 & 89.3092 & $\begin{array}{l}\text { ALA28, VAL30, ARG31, } \\
\text { TRP32, PRO34, ALA35 }\end{array}$ & VAL30, TRP32, PRO34 & $\begin{array}{l}\text { ILE160, ASN162, ARG323, } \\
\text { LYS505 }\end{array}$ & ILE160 \\
\hline 35 & SFTTTAER & 1 & 111.511 & ARG31, TRP32 & $\begin{array}{l}\text { PHE29, VAL30, ARG31, } \\
\text { TRP32 }\end{array}$ & THR159, LYS505 & $\begin{array}{l}\text { CYS153, SER156, THR159, } \\
\text { ASN162 }\end{array}$ \\
\hline 37 & TLEEEKLQ & 1 & 127.638 & ARG31, TRP32, PRO34 & $\begin{array}{l}\text { ALA28, TRP32, LEU33, } \\
\text { PRO34 }\end{array}$ & $\begin{array}{l}\text { ILE160, ASN162, ARG323, } \\
\text { LYS505 }\end{array}$ & $\begin{array}{l}\text { ALA152, CYS153, THR159, } \\
\text { ILE160, ARG323 }\end{array}$ \\
\hline 40 & FLNNNALT & 1 & 88.3879 & ARG31, TRP32 & ARG31 & THR159, ARG323 & $\begin{array}{c}\text { ILE160, ASN162, SER319, } \\
\text { VAL320, ARG323 }\end{array}$ \\
\hline 41 & LEVLGVPA & 1 & 96.8835 & $\begin{array}{l}\text { PHE29, VAL30, ARG31, } \\
\text { TRP32, LEU33, PRO34 }\end{array}$ & $\begin{array}{l}\text { ALA28, VAL30, ARG31, } \\
\text { PRO34 }\end{array}$ & $\begin{array}{l}\text { CYS153, THR159, ILE160, } \\
\text { ASN162, ARG323, LYS505 }\end{array}$ & ILE160 \\
\hline 42 & KLDEKIVQ & 1 & 102.044 & $\begin{array}{l}\text { VAL30, ARG31, LEU33, } \\
\text { PRO34 }\end{array}$ & $\begin{array}{l}\text { ALA28, ARG31, PRO34, } \\
\text { SER42 }\end{array}$ & ARG323 & $\begin{array}{c}\text { ALA152, CYS153, ILE160, } \\
\text { ARG161, ASN162, SER319, } \\
\text { ARG323, LYS505 }\end{array}$ \\
\hline 44 & TVPIYEGY & 1 & 88.1488 & VAL30, TRP32, SER42 & ALA28, ARG31, TRP32 & $\begin{array}{l}\text { ALA152, CYS153, SER156, } \\
\text { THR159, ILE160, ARG161, } \\
\text { ASN162 }\end{array}$ & ASN162 \\
\hline 52 & SVKNTAGL & 1 & 89.225 & ARG31, LEU33 & ALA28, ARG31 & CYS153, ASN162, ARG323 & ILE160, ARG323, LYS505 \\
\hline 53 & ADINAADQ & 1 & 121.529 & ARG31 & $\begin{array}{l}\text { ARG31, TRP32, LEU33, } \\
\text { PRO34 }\end{array}$ & $\begin{array}{l}\text { ALA152, CYS153, ILE160, } \\
\text { ASN162 }\end{array}$ & $\begin{array}{l}\text { THR159, ILE160, ASN162, } \\
\text { ARG323, LYS505 }\end{array}$ \\
\hline 54 & KTWVKELQ & 1 & 80.8878 & $\begin{array}{l}\text { ALA28, ARG31, PRO34, } \\
\text { SER42 }\end{array}$ & ARG31, TRP32, & $\begin{array}{l}\text { CYS153, THR159, ILE160, } \\
\text { ASN162 }\end{array}$ & ILE160, ARG323, LYS505 \\
\hline 57 & EEQVAAIR & 1 & 124.143 & ARG31, TRP32 & $\begin{array}{l}\text { PHE29, ARG31, PRO34, } \\
\text { ALA35 }\end{array}$ & $\begin{array}{l}\text { THR159, ILE160, ARG323, } \\
\text { PHE439 }\end{array}$ & $\begin{array}{l}\text { ALA152, CYS153, THR159, } \\
\text { ILE160, SER319, ARG323, } \\
\text { LYS505 }\end{array}$ \\
\hline
\end{tabular}


Table 3. Cont

\begin{tabular}{|c|c|c|c|c|c|c|c|}
\hline Peptide no. & Peptide Sequence & Consensus Score & $\begin{array}{c}\text {-CDOCKER } \\
\text { Interaction Energy }\end{array}$ & $\begin{array}{c}\text { Interactions with A Chain } \\
\text { of MPO }\end{array}$ & $\begin{array}{c}\text { Interactions with B Chain } \\
\text { of MPO }\end{array}$ & $\begin{array}{l}\text { Interactions with C Chain } \\
\text { of MPO }\end{array}$ & $\begin{array}{l}\text { Interactions with D Chain } \\
\text { of MPO }\end{array}$ \\
\hline 63 & MGSTLIMLL & 1 & 120.627 & $\begin{array}{l}\text { VAL30, ARG31, TRP32, } \\
\text { LEU33, PRO34 }\end{array}$ & ALA28, VAL30, ARG31 & $\begin{array}{l}\text { ILE160, ASN162, PHE439, } \\
\text { LYS505 }\end{array}$ & $\begin{array}{l}\text { PRO151, CYS153, SER156, } \\
\text { THR159, ILE160, ANS162 }\end{array}$ \\
\hline 70 & LGKTVPDDV & 1 & 88.3103 & $\begin{array}{l}\text { ARG31, TRP32, LEU33, } \\
\text { PRO34 }\end{array}$ & PHE29, ARG31, PRO34 & $\begin{array}{l}\text { ILE160, ASN162, ARG323, } \\
\text { LYS505 }\end{array}$ & $\begin{array}{l}\text { PRO151, ALA152, CYS153, } \\
\text { ILE160, ARG161, ANS162, } \\
\text { ARG323 }\end{array}$ \\
\hline 73 & QVITIGNER & 1 & 113.155 & $\begin{array}{l}\text { ALA28, VAL30, ARG31, } \\
\text { PRO34 }\end{array}$ & $\begin{array}{l}\text { ALA28, VAL30, ARG31, } \\
\text { LEU33, ALA35 }\end{array}$ & ARG323, LYS505 & $\begin{array}{l}\text { ALA152, PRO154, GLY155, } \\
\text { SER156, THR15, ILE160, } \\
\text { ANS162, SER319, ARG323, } \\
\text { LYS505 }\end{array}$ \\
\hline 74 & LSDLSPFPG & 1 & 82.875 & TRP32 & $\begin{array}{l}\text { ALA28, PHE29, ARG31, } \\
\text { TRP32, PRO34 }\end{array}$ & $\begin{array}{l}\text { ALA152, CYS153, THR159, } \\
\text { ILE160, ASN162, ARG323, } \\
\text { LYS505 }\end{array}$ & $\begin{array}{l}\text { ALA152, CYS153, THR159, } \\
\text { ILE160, ARG161, ANS162, } \\
\text { PHE439 }\end{array}$ \\
\hline 78 & VGYDALTDQ & 1 & 133.602 & $\begin{array}{l}\text { ALA28, VAL30, ARG31, } \\
\text { TRP32 }\end{array}$ & ARG31, PRO34, ALA35 & $\begin{array}{l}\text { ALA152, CYS153, ARG323, } \\
\text { LYS505 }\end{array}$ & $\begin{array}{l}\text { PRO151, CYS153, SER156, } \\
\text { THR159, ILE160, ARG161, } \\
\text { ANS162, ARG323, LYS505 }\end{array}$ \\
\hline 81 & IEAIDQVGS & 1 & 124.082 & ARG31, LEU33 & VAL30, ARG31, SER42 & $\begin{array}{l}\text { CYS153, THR159, ASN162, } \\
\text { ARG323, PHE439 }\end{array}$ & $\begin{array}{c}\text { CYS153, GLY155, SER156, } \\
\text { THR159, ILE160, ASN162, } \\
\text { ARG323, LYS505 }\end{array}$ \\
\hline 82 & MKNPKASVL & 1 & 48.301 & ARG31, TRP32 & - & ILE160, LYS505 & $\begin{array}{l}\text { SER156, THR159, ILE160, } \\
\text { ASN162, ARG323, PHE439 }\end{array}$ \\
\hline 84 & LIIIIAAMT & 1 & 80.6012 & VAL30, ARG31, TRP32 & $\begin{array}{l}\text { ALA28, ARG31, PRO34, } \\
\text { ALA35 }\end{array}$ & ILE160, ASN162 & CYS153, ILE160, ASN162 \\
\hline 90 & AGFAGDDAPR & 1 & 118.225 & ARG31, PRO34 & $\begin{array}{l}\text { ALA28, VAL30, ARG31, } \\
\text { PRO34 }\end{array}$ & ARG323 & $\begin{array}{l}\text { CYS153, SER156, THR159, } \\
\text { ILE160, ASN162, ARG323 }\end{array}$ \\
\hline 91 & DAVTYTEHAK & 1 & 130.855 & VAL30, ARG31, PRO34 & ARG31, PHE41 & ILE160, ARG323, LYS505 & $\begin{array}{l}\text { CYS153, PRO154, GLY155, } \\
\text { SER156, THR159, ILE160, } \\
\text { ARG161, ASN162, ARG323, } \\
\text { PHE439 }\end{array}$ \\
\hline 94 & VLMILPSVTG & 1 & 80.7513 & $\begin{array}{l}\text { VAL30, ARG31, PRO34, } \\
\text { ALA35 }\end{array}$ & $\begin{array}{l}\text { ALA28, ARG31, TRP32, } \\
\text { LEU33, PRO34 }\end{array}$ & ILE160, ASN162, ARG323 & $\begin{array}{l}\text { PRO151, ALA152, CYS153, } \\
\text { GLY155, THR159, ILE160, } \\
\text { ARG161, ARG323, PHE439 }\end{array}$ \\
\hline 107 & DSGLLTPESV & 1 & 88.9027 & ALA28, ARG31, SER42 & ARG31, TRP32, PRO34 & $\begin{array}{l}\text { CYS153, GLY155, SER156, } \\
\text { THR159, ILE160, ARG161, } \\
\text { ASN162, ARG323, LYS505 }\end{array}$ & ILE160 \\
\hline 109 & VEQEILETGI & 1 & 95.3997 & ARG31, TRP32 & $\begin{array}{l}\text { VAL30, ARG31, TRP32, } \\
\text { PHE41 }\end{array}$ & $\begin{array}{l}\text { THR159, ASN162, ARG323, } \\
\text { LYS505 }\end{array}$ & $\begin{array}{l}\text { ALA152, PRO154, GLY155, } \\
\text { SER156, , THR159, ILE160, } \\
\text { ARG161, ANS162, ARG323, } \\
\text { LYS505, }\end{array}$ \\
\hline 113 & SDDLDLGQVG & 1 & 63.6376 & ARG31, PRO34 & $\begin{array}{l}\text { VAL30, ARG31, TRP32, } \\
\text { PRO34 }\end{array}$ & ARG323, LYS505 & $\begin{array}{l}\text { ARG148, CYS153, GLY155, } \\
\text { SER156, THR15, ILE160, } \\
\text { ARG161, ANS162 }\end{array}$ \\
\hline 114 & HQGVMVGMGQK & 1 & 108.89 & $\begin{array}{l}\text { ALA28, VAL30, ARG31, } \\
\text { TPR32 }\end{array}$ & ARG31, ASP39, SER42 & THR159, PHE439, LYS505 & $\begin{array}{l}\text { PRO151, ALA152, CYS153, } \\
\text { THR159, ILE160, ARG161, } \\
\text { ANS162 }\end{array}$ \\
\hline
\end{tabular}


Table 3. Cont

\begin{tabular}{|c|c|c|c|c|c|c|c|}
\hline Peptide no. & Peptide Sequence & Consensus Score & $\begin{array}{c}- \text { CDOCKER } \\
\text { Interaction Energy }\end{array}$ & $\begin{array}{l}\text { Interactions with A Chain } \\
\text { of MPO }\end{array}$ & $\begin{array}{c}\text { Interactions with B Chain } \\
\text { of MPO }\end{array}$ & $\begin{array}{l}\text { Interactions with C Chain } \\
\text { of MPO }\end{array}$ & $\begin{array}{c}\text { Interactions with D Chain } \\
\text { of MPO }\end{array}$ \\
\hline 122 & LSAAGLEAGNV & 1 & 104.596 & ARG31, TRP32 & ARG31, SER42 & THR159, ARG323 & $\begin{array}{c}\text { ALA152, CYS153, PRO154, } \\
\text { GLY155, SER156, THR159, } \\
\text { ILE160, ANS162, SER319, } \\
\text { ASP321, ARG323 }\end{array}$ \\
\hline 123 & ATAASSSSLEK & 1 & 107.999 & ARG31, TRP32, PRO34 & $\begin{array}{l}\text { VAL30, ARG31, ASP39, } \\
\text { SER42 }\end{array}$ & ARG323, PHE439, LYS505 & $\begin{array}{l}\text { CYS153, GLY155, THR159, } \\
\text { ILE160, ARG161, ASN162 }\end{array}$ \\
\hline 124 & VVVYGGVAVNH & 1 & 58.4842 & ARG31 & $\begin{array}{l}\text { ALA28, ARG31, PRO34, } \\
\text { PHE41, SER42 }\end{array}$ & ASN162, ARG323, PHE439 & $\begin{array}{l}\text { ARG148, PRO151, ALA152, } \\
\text { CYS153, SER156, THR159, } \\
\text { ILE160, ANS162, ARG323 }\end{array}$ \\
\hline 130 & KAGSERNVLIF & 1 & 127.874 & $\begin{array}{l}\text { ARG31, TRP32, PRO34, } \\
\text { ALA35, ASP39, SER42 }\end{array}$ & ARG31, PRO34 & $\begin{array}{l}\text { CYS153, PRO154, GLY155, } \\
\text { SER156, SER156, THR159, } \\
\text { ILE160, ARG161, ASN162, } \\
\text { PHE439, LYS505 }\end{array}$ & $\begin{array}{l}\text { ILE160, ARG161, ARG323, } \\
\text { LYS505 }\end{array}$ \\
\hline 137 & IGLFGGAGVGK & 1 & 104.383 & ALA28, ARG31, PRO34 & $\begin{array}{l}\text { PHE29, ARG31, PRO34, } \\
\text { PHE41 }\end{array}$ & ARG323, PHE439, LYS505 & $\begin{array}{l}\text { PRO151, CYS153, SER156, } \\
\text { THR159, ILE160, ARG323 }\end{array}$ \\
\hline 139 & TLSIQNDQASQR & 1 & 116.278 & ARG31, TRP32 & - & $\begin{array}{l}\text { ILE160, ARG161, ASN162, } \\
\text { ARG323, PHE439, CYS497, } \\
\text { LYS505 }\end{array}$ & $\begin{array}{l}\text { ARG148, CYS153, ARG161, } \\
\text { ASN162, SER156, THR159, } \\
\text { ILE160, ARG323 }\end{array}$ \\
\hline 142 & DSYVGDEAQSKR & 1 & 91.8078 & PRO34 & ARG31 & ARG323, PHE439 & $\begin{array}{l}\text { CYS153, GLY155, SER156, } \\
\text { THR159, ILE160, ARG161, } \\
\text { SER319, ARG323, ARG504 }\end{array}$ \\
\hline 152 & YISHIELAFSSV & 1 & 122.83 & ARG31, TRP32, PRO34 & ALA28, TRP32 & ARG323, PHE439, LYS505 & $\begin{array}{l}\text { PRO151, CYS153, PRO154, } \\
\text { GLY155, SER156, THR159, } \\
\text { ILE160, ASN162 }\end{array}$ \\
\hline 154 & EGGGIVESIGEG & 1 & 150.197 & ARG31, TRP32, PRO34 & ARG31, TRP32, SER42 & ALA152, ARG323, LYS505 & $\begin{array}{c}\text { ALA152, CYS153, SER156, } \\
\text { ILE160, ARG161, ARG323, } \\
\text { PHE439 }\end{array}$ \\
\hline 155 & CRPGALESGPAL & 1 & 91.9951 & ALA28, PRO34 & ARG31 & $\begin{array}{l}\text { ALA152, CYS153, PRO154, } \\
\text { GLY155, SER156, ILE160, } \\
\text { ARG161, ASN162, ARG323 }\end{array}$ & $\begin{array}{l}\text { ILE160, ARG323, PHE439, } \\
\text { LYS505 }\end{array}$ \\
\hline 156 & FNLWGLSCSSLL & 1 & 88.0987 & $\begin{array}{l}\text { VAL30, ARG31, TRP32, } \\
\text { PRO34 }\end{array}$ & $\begin{array}{l}\text { VAL30, ARG31, PRO34, } \\
\text { SER42, LEU43 }\end{array}$ & ASN162 & $\begin{array}{l}\text { PRO123, ARG148, PRO151, } \\
\text { CYS153, GLY155, SER156, } \\
\text { THR159, ILE160, ARG161, } \\
\text { ASN162, ASP321, ARG323 }\end{array}$ \\
\hline 161 & AKCGAYQGQVLIF & 1 & 114.346 & ARG31, TRP32 & TRP32 & $\begin{array}{l}\text { ILE160, ASN162, LYS308, } \\
\text { ARG323, PHE439 }\end{array}$ & $\begin{array}{l}\text { CYS153, SER156, THR159, } \\
\text { ILE160, ARG161, ASN162 }\end{array}$ \\
\hline 169 & FTQAGSEVSALLGR & 1 & 130.617 & ARG31, PRO34 & VAL30, ARG31 & - & $\begin{array}{c}\text { CYS153, GLY155, SER156, } \\
\text { ILE160, ARG161, ASN162, } \\
\text { ARG323, PHE439 }\end{array}$ \\
\hline 170 & TTGIVLDSGDGVTH & 1 & 95.5298 & ARG31, PRO34 & $\begin{array}{l}\text { VAL30, ARG31, PRO34, } \\
\text { SER42 }\end{array}$ & $\begin{array}{c}\text { ASN162, ARG323, ARG438, } \\
\text { PHE439, GLY441 }\end{array}$ & $\begin{array}{c}\text { PRO123, PRO151, CYS153, } \\
\text { PRO154, GLY155, SER156, } \\
\text { THR159, ILE160, ARG161, } \\
\text { SER319, ARG323 }\end{array}$ \\
\hline
\end{tabular}


Table 3. Cont

\begin{tabular}{|c|c|c|c|c|c|c|c|}
\hline Peptide no. & Peptide Sequence & Consensus Score & $\begin{array}{c}\text {-CDOCKER } \\
\text { Interaction Energy }\end{array}$ & $\begin{array}{l}\text { Interactions with A Chain } \\
\text { of MPO }\end{array}$ & $\begin{array}{c}\text { Interactions with B Chain } \\
\text { of MPO }\end{array}$ & $\begin{array}{c}\text { Interactions with C Chain } \\
\text { of MPO }\end{array}$ & $\begin{array}{c}\text { Interactions with D Chain } \\
\text { of MPO }\end{array}$ \\
\hline 172 & AHGGYSVFAGVGER & 1 & 106.868 & VAL30, ARG31 & $\begin{array}{l}\text { PHE29, VAL30, ARG31, } \\
\text { TRP32, SER42 }\end{array}$ & $\begin{array}{l}\text { CYS153, ASN162, PHE439, } \\
\text { LYS505 }\end{array}$ & $\begin{array}{l}\text { ARG148, ALA152, CYS153, } \\
\text { PRO154, GLY155, THR159, } \\
\text { ARG161, ASN162, ARG323 } \\
\text { LYS505 }\end{array}$ \\
\hline 177 & ELPDGQVITIGNER & 1 & 113.61 & $\begin{array}{l}\text { ARG31, TRP32, PRO34, } \\
\text { ASP39, SER42 }\end{array}$ & $\begin{array}{l}\text { ALA28, ARG31, TRP32, } \\
\text { LEU33, PRO34 }\end{array}$ & $\begin{array}{l}\text { CYS153, GLY155, SER156, } \\
\text { THR159, ILE160, ARG161, } \\
\text { ASN162, SER319. ARG323, } \\
\text { LYS505 }\end{array}$ & THR159, ASP321, ARG323 \\
\hline 178 & SAYLVLTITIAAMT & 1 & 111.103 & ARG31, TRP32, PRO34 & ALA28, ARG31, PHE41 & $\begin{array}{l}\text { CYS153, ILE160, ARG438, } \\
\text { PHE439, LYS505 }\end{array}$ & $\begin{array}{l}\text { ALA152, CYS153, GLY155, } \\
\text { SER156, THR119, ILE160, } \\
\text { ARG161, ASN162, ARG323 }\end{array}$ \\
\hline 180 & WEDLANEIQEELNK & 1 & 107.719 & ARG31, TRP32 & $\begin{array}{l}\text { VAL30, ARG31, TRP32, } \\
\text { PRO34, PHE41 }\end{array}$ & $\begin{array}{l}\text { THR159, ARG438, CYS440, } \\
\text { GLY441, LYS505 }\end{array}$ & $\begin{array}{l}\text { PRO123, ARG148, PRO151, } \\
\text { ALA152, CYS 153, THR159, } \\
\text { ILE160, ARG161, ASN162, } \\
\text { ARG323, LYS505 }\end{array}$ \\
\hline 186 & EQEGGLGNFMNFMKENG & 1 & 163.68 & TRP32, PRO34 & $\begin{array}{l}\text { ALA28, PHE29, ARG31, } \\
\text { LEU33, PRO34, PHE41, } \\
\text { PRO101, PRO103 }\end{array}$ & $\begin{array}{l}\text { ILE160, ARG323, PHE439, } \\
\text { CYS440 }\end{array}$ & $\begin{array}{l}\text { PRO124, PRO151, CYS153, } \\
\text { SER156, THR159, ILE160, } \\
\text { ARG161, ASN162, SER319 }\end{array}$ \\
\hline 51 & LILLIRAK & 0 & 74.004 & $\begin{array}{c}\text { ALA28, PHE29, ARG31, } \\
\text { TRP32, PRO34 }\end{array}$ & $\begin{array}{l}\text { ALA28, ARG31, PRO34, } \\
\text { SER42 }\end{array}$ & ILE160, PHE439, LYS505 & $\begin{array}{l}\text { ALA152, CYS153, SER156, } \\
\text { ILE160, ARG161, ANS162 }\end{array}$ \\
\hline 59 & LARDKAAN & 0 & 94.6022 & ARG31, TRP32 & $\begin{array}{l}\text { PHE29, VAL30, ARG31, } \\
\text { LEU33 }\end{array}$ & $\begin{array}{l}\text { THR159, ILE160, ASN162, } \\
\text { ARG323, LYS505 }\end{array}$ & THR159 \\
\hline 67 & VLFPLTTLQ & 0 & 72.9901 & VAL30 & ARG31, TRP32, SER42 & CYS153, LYS505 & $\begin{array}{l}\text { PRO151, ALA152, CYS153, } \\
\text { SER156, ARG161, ANS162, } \\
\text { ARG323 }\end{array}$ \\
\hline 72 & SMSFFGLIM & 0 & 86.9571 & - & $\begin{array}{c}\text { ALA28, ARG31, TRP32, } \\
\text { PRO34 }\end{array}$ & ASN162, ARG323, PHE439 & $\begin{array}{c}\text { PRO151, ALA152, ILE160, } \\
\text { ARG161, ASN162, ASP321, } \\
\text { LYS505 }\end{array}$ \\
\hline 85 & ISGLIYEETR & 0 & 75.3523 & ARG31, TRP32, SER42 & $\begin{array}{c}\text { ALA28, ARG31, LEU33, } \\
\text { PRO34 }\end{array}$ & $\begin{array}{l}\text { CYS153, PRO154, GLY155, } \\
\text { SER156, THR159, ILE160, } \\
\text { ASN162, ARG323, LYS505 }\end{array}$ & CYS153, ARG323 \\
\hline 99 & VVTSGNSLNG & 0 & 93.2669 & VAL30, ARG31, TRP32 & PHE29, ARG31, TRP32 & ILE160, ARG323, PHE439 & $\begin{array}{l}\text { ALA152, CYS153, ILE160, } \\
\text { ANS162, LYS505 }\end{array}$ \\
\hline 117 & VEIIANDQGNR & 0 & 114.499 & ARG31, PRO34 & VAL30, ARG31, SER42 & ASN162, ARG323, PHE439 & $\begin{array}{l}\text { ARG148, CYS153, GLY155, } \\
\text { SER156, THR159, ILE160, } \\
\text { ARG161, ASN162, ARG323 }\end{array}$ \\
\hline 121 & PTKVGINGFGR & 0 & 81.1789 & $\begin{array}{l}\text { ALA28, PHE29, ARG31, } \\
\text { TRP32 }\end{array}$ & ALA28, SER42 & LYS505 & $\begin{array}{c}\text { CYS153, GLY155, SER156, } \\
\text { THR159, ILE160 }\end{array}$ \\
\hline 140 & ELISNASDALDK & 0 & 74.9956 & ARG31, TRP32, TRP47 & LEU33 & $\begin{array}{c}\text { ARG148, PRO151, CYS153, } \\
\text { PRO154, THR159, ILE160, } \\
\text { ARG161, ASN162, ARG323, } \\
\text { LYS505 }\end{array}$ & ARG323 \\
\hline
\end{tabular}


Table 3. Cont

\begin{tabular}{|c|c|c|c|c|c|c|c|}
\hline Peptide no. & Peptide Sequence & Consensus Score & $\begin{array}{c}\text {-CDOCKER } \\
\text { Interaction Energy }\end{array}$ & $\begin{array}{l}\text { Interactions with A Chain } \\
\text { of MPO }\end{array}$ & $\begin{array}{c}\text { Interactions with B Chain } \\
\text { of MPO }\end{array}$ & $\begin{array}{l}\text { Interactions with C Chain } \\
\text { of MPO }\end{array}$ & $\begin{array}{c}\text { Interactions with D Chain } \\
\text { of MPO }\end{array}$ \\
\hline 162 & LLTLATCVGDGPA & 0 & 72.2681 & $\begin{array}{l}\text { VAL30, ARG31, TRP32, } \\
\text { SER42 }\end{array}$ & ARG31 & $\begin{array}{l}\text { CYS153, GLY155, SER156, } \\
\text { THR159, ILE160, ARG161, } \\
\text { ASN162 }\end{array}$ & CYS153, LYS505 \\
\hline 164 & RSLGDFACQLEHL & 0 & 75.728 & ARG31, SER42 & TRP32 & $\begin{array}{l}\text { PRO151, CYS153, GLY155, } \\
\text { SER156, THR159, ILE160, } \\
\text { ARG161, LYS505 }\end{array}$ & $\begin{array}{l}\text { THR159, LYS308, ARG323, } \\
\text { PHE439, CYS440 }\end{array}$ \\
\hline 171 & LISWYDNEYGYSNR & 0 & 137.019 & $\begin{array}{c}\text { ALA28, ARG31, TRP32, } \\
\text { PRO34 }\end{array}$ & PHE29, PHE41, SER42 & THR159, ASN162 & $\begin{array}{c}\text { ALA152, CYS153, PRO154, } \\
\text { SER156, THR159, ARG161, } \\
\text { ASN162, VAL320, ASP321, } \\
\text { ARG323 }\end{array}$ \\
\hline 191 & $\begin{array}{l}\text { LVQDVANNTNEEAGD } \\
\text { GTTTATVLAR }\end{array}$ & 0 & 120.381 & $\begin{array}{l}\text { VAL30, ARG31, TRP32, } \\
\text { LEU33 }\end{array}$ & VAL30, TRP32, LEU43 & THR159, ILE160, PHE439 & $\begin{array}{l}\text { CYS153, GLY155, SER156, } \\
\text { ASN157, THR159, ILE160, } \\
\text { ARG161, ASN317, SER319, } \\
\text { ARG323, ARG504, LYS505 }\end{array}$ \\
\hline 192 & $\begin{array}{l}\text { AQTISYEVSMALVLL } \\
\text { FPLFLGGSFSF }\end{array}$ & 0 & 185.828 & TRP32 & $\begin{array}{l}\text { ARG31, TRP32, PRO34, } \\
\text { SER42 }\end{array}$ & $\begin{array}{l}\text { ASN162, ARG323, PHE439, } \\
\text { GLY441, PRO443, LYS505 }\end{array}$ & $\begin{array}{l}\text { GLN122, PRO123, CYS153, } \\
\text { PRO154, GLY15, SER156, } \\
\text { THR159, ILE160, ARG161, } \\
\text { ASN162, ARG323, LYS505 }\end{array}$ \\
\hline
\end{tabular}


Reference peptide hLF1-11 and peptide no. 39 had similar interaction energy around a value of -120. As shown in Table 3, the interaction sites between peptide no. 39 and amino acids residues of MPO were similar to those between the reference peptide and MPO. For the LF1-11, the interactions with MPO were amino acids ARG 31 on the A chain, VAL30, ARG31, and TRP32 on the B chain, ARG323 and LYS505 on the C chain, and ALA152, CYS153, ILE160, and LYS505 on the D chain. Nevertheless, peptide no. 39 seemed to have a stronger binding with MPO than LF1-11, as not only the mentioned amino acids above, but also the TRP32 on the A chain of MPO, ALA28, PHE29 on the B chain, ILE160 on the C chain, and THR159 and ARG323 on the D chain were also involved in the peptide no. 39 and MPO interactions. The binding of peptide no. 39 onto these amino acid residues may have interrupted the rigid hydrogen bond, electrostatic interaction, and covalent bond network in the active site that are important for catalysis by MPO [34,35].

As shown in Figure 4, there is structure similarity observed between reference hLF1-11 and peptide no. 39. Peptide no. 39 physically suited well in the docking pocket of MPO with the similar length. It could be observed from the docking model in Figure 4 that peptide no. 39 was able to block the active sites of MPO to inhibit the catalytic activity of MPO. From the structure comparison of hLF1-11 and peptide no. 39, the interactions involved were similar. The charge interactions were found between peptides (hLF1-11 and peptide no. 39) and MPO residues ARG323 and LYS505, for example, via the -COO group of peptide no. 39 and -NH group of arginine residue in MPO. Peptide no. 39 also formed hydrogen bonds from the $-\mathrm{C}=\mathrm{O}$ and $-\mathrm{NH}$ groups of peptides to the ARG31 and ILE160 residues in $\mathrm{MPO}$, and these two residues were also involved in hydrogen bond formation between reference hLF1-11 and MPO pocket. $\mathrm{C}-\mathrm{H}$ bonds were predicted to be formed between peptide no. 39 and amino acid residues VAL30, TRP32, and THR159, which were also associated in the C-H bond interactions between reference and MPO. The difference in the predicted interactions was that 1 pi sulfur interaction was predicted between reference hLF1-11 and PHE439 in MPO, as well as 3 acyl interactions predicted between peptide no. 39 and ALA152, CYS153, and ALA28 in MPO. The molecular docking (Figure 4) indicated that peptide no. 39 (DTETGVPT) was similar in structure as well as the interactions with amino acid residues in the MPO active site, which made it possible for peptide no. 39 to perform antioxidative activity in vivo.

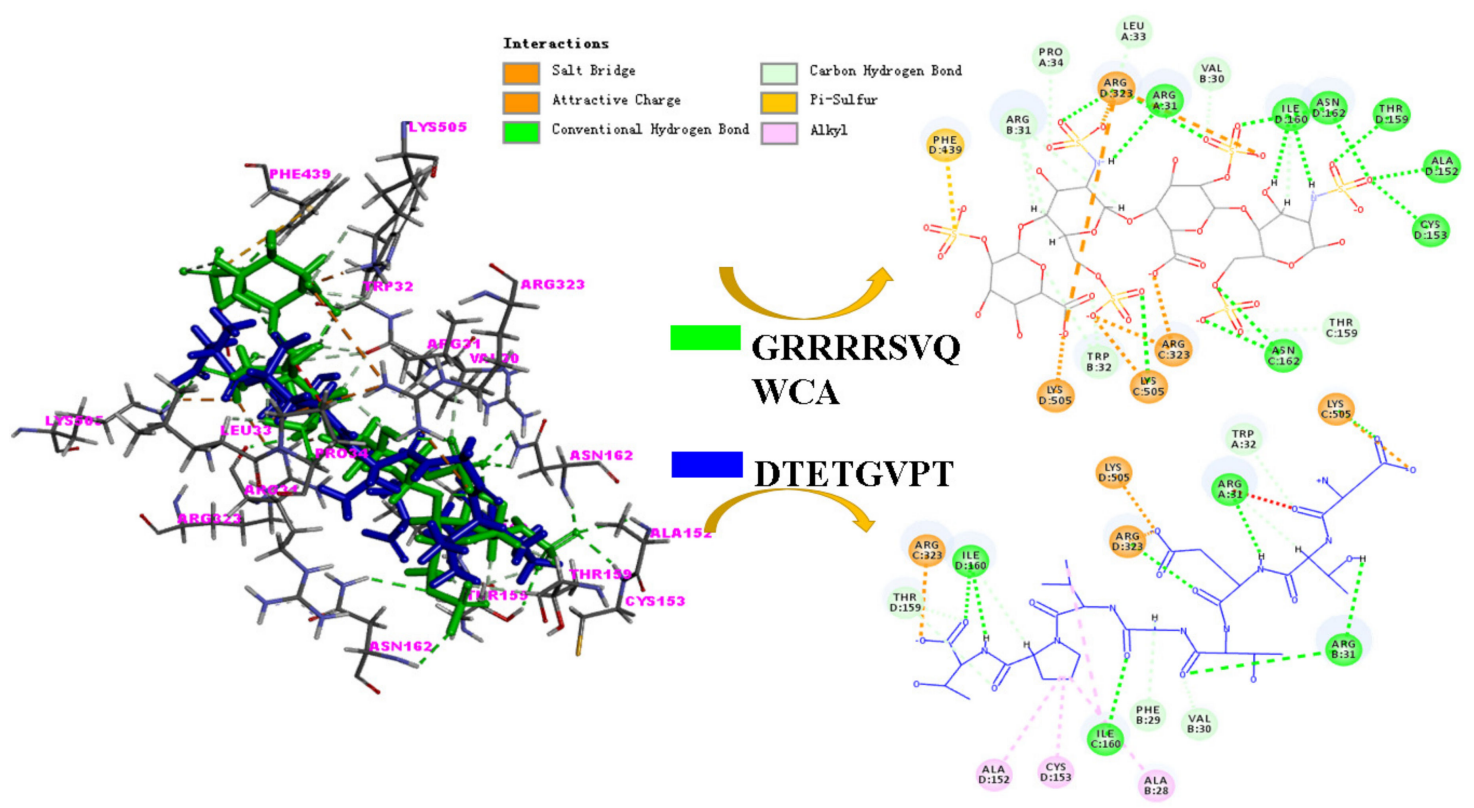

Figure 4. Molecular docking model of the interactions between hLF1-11(GRRRRSVQWCA) and MPO, as well as between peptide no. 39 (DTETGVPT) with the active sites of MPO (Protein Data Bank (PDB) ID: 3F9P). The structure of hLF1-11 and peptide no. 39 are shown in green and blue stick representations, respectively, in the docking model shown on the left. The amino acid residues around 
the MPO active site that are involved in the interactions are labelled in magenta color. The interactions between peptides (hLF1-11 or peptide no. 39) and MPO active site are labelled in different colors for better visualization (charge interactions in orange color, conventional hydrogen bond in emerald green color, carbon hydrogen bond in light green color, pi sulfur interaction in light orange color, and alkyl interaction in light pink color).

\section{Materials and Methods}

\subsection{Materials and Reagents}

Fresh false abalone were purchased from the local market in Dalian, China. The water content and protein content of the false abalone samples were $77.53 \pm 2.13 \%$ and $18.24 \pm 1.03 \%$ using methods GB/T5009.3-2016 and GB/T5009.5-2016, respectively. Five proteases including pepsin ( $\geq 400$ units $/ \mathrm{mg}$ protein), alcalase ( $\geq 200$ units $/ \mathrm{mg}$ protein), trypsin ( $\geq 2500$ USP units/mg protein), neutrase ( $\geq 600$ units $/ \mathrm{mg}$ protein), and flavourzyme ( $\geq 300$ units $/ \mathrm{mg}$ protein) were purchased from Sinopharm Chemical Reagent Co., Ltd., Shanghai, China. Other chemicals and reagents were of analytical degree.

\subsection{Proteolytic Hydrolysis of False Abalone}

False abalone samples were blended in different buffer solutions ( $\mathrm{pH}$ 2.0, 7.0, 8.0, and 10.0) at the ratio of $3 \%(\mathrm{w} / \mathrm{v})$. Five proteases were added at a concentration of $7 \%(\mathrm{w} / \mathrm{v})$ individually. The commercial recommended hydrolysis temperatures and $\mathrm{pH}$ values for each protease were applied as: pepsin at $37^{\circ} \mathrm{C}, \mathrm{pH} \mathrm{2.0;}$; alcalase at $50{ }^{\circ} \mathrm{C}, \mathrm{pH} 10.0$; trypsin at $50^{\circ} \mathrm{C}, \mathrm{pH} 8.0$; neutrase at $50{ }^{\circ} \mathrm{C}$, $\mathrm{pH} 7.0$; and flavourzyme at $55^{\circ} \mathrm{C}, \mathrm{pH}$ 7.0. After $3 \mathrm{~h}$ hydrolysis, the mixtures were treated at $100^{\circ} \mathrm{C}$ for $10 \mathrm{~min}$ to inactivate the proteases, followed by centrifugation at $8000 \mathrm{rpm}$ for $15 \mathrm{~min}$. The supernatants were collected as false abalone hydrolysates.

\subsection{Determination of Protein Concentration and Hydrolysis Degree}

The protein concentration of hydrolysate was measured using the BCA Protein Assay Reagent Kit (Beyotime Biotechnology Co., Shanghai, China) following the instructions. The hydrolysis degree of hydrolysate was determined based on the content of amino nitrogen using the formol-titration method according to GB/T5009.39-2003. Briefly, $1 \mathrm{~mL}$ hydrolysate sample was diluted with $60 \mathrm{~mL}$ distilled water and was then titrated to $\mathrm{pH} 8.2$ using $0.05 \mathrm{M} \mathrm{NaOH}$ solution $\left(\mathrm{V}_{\mathrm{a}}\right)$. Formaldehyde solution of $10 \mathrm{~mL}$ was added, and the mixture was titrated continuously to $\mathrm{pH} 9.2$ using a $0.05 \mathrm{M} \mathrm{NaOH}$ solution $\left(\mathrm{V}_{\mathrm{b}}\right)$. The $\mathrm{NaOH}$ solution consumed after formaldehyde addition was $\mathrm{V}_{\text {sample }}$ (i.e., $\mathrm{V}_{\mathrm{b}}-\mathrm{V}_{\mathrm{a}}$ ). Blank was performed using distilled water instead of hydrolysates, and the $\mathrm{NaOH}$ solution consumed after formaldehyde addition was $V_{\text {blank. }}$. The hydrolysis degree was calculated using Equations (3) and (4) with samples before and after hydrolysis. Total amino nitrogen was measured using samples after complete hydrolysis with acid treatment for $12 \mathrm{~h}$.

$$
\begin{aligned}
& \mathrm{X}(\text { Amino nitrogen content, } \mathrm{g} / 100 \mathrm{~mL})=\left(\mathrm{V}_{\text {sample }}-\mathrm{V}_{\text {blank }}\right) \times \mathrm{c} \times 0.014 \times 100 \\
& \text { Hydrolysis degree }(\%)=\left(\mathrm{X}_{\text {before hydrolysis }}-\mathrm{X}_{\text {after hydrolysis }}\right) / \mathrm{X}_{\text {complete hydrolysis }}
\end{aligned}
$$

where $\mathrm{c}$ is the concentration of $\mathrm{NaOH}$ solution used, and 0.014 is the nitrogen content equivalent to $1 \mathrm{~mL} 1 \mathrm{M} \mathrm{NaOH}$ solution.

\subsection{Antioxidant Activity Determination of Hydrolysates Using ABTS ${ }^{+\bullet}$ Assay}

The $\mathrm{ABTS}^{+\bullet}$ free radical scavenging activity was determined using the method as described by Li et al. [36] with slight modification. Briefly, $\mathrm{ABTS}^{+\bullet}$ free radical was generated in darkness using $10 \mathrm{~mL}$ of $7 \mathrm{mM}$ ABTS and $176 \mu \mathrm{L}$ of $130 \mathrm{mM}$ potassium persulfate for $16 \mathrm{~h}$. The ABTS ${ }^{+\bullet}$ solution was diluted with $60 \%$ ethanol to an absorbance of $0.70 \pm 0.02$ at $733 \mathrm{~nm}$. A hydrolysate sample of $1 \mathrm{~mL}$ 
was mixed with $3.9 \mathrm{~mL} \mathrm{ABTS}{ }^{+\bullet}$ solution, and the absorbance was measured after $10 \mathrm{~min}$ at $733 \mathrm{~nm}$ $\left(\mathrm{A}_{\text {sample }}\right)$. Blank was measured using ethanol instead of the hydrolysate sample, and the absorbance measured as $\mathrm{A}_{\text {blank }}$. $\mathrm{ABTS}^{+} \bullet$ free radical scavenging activity was calculated using Equation (5):

$$
\mathrm{ABTS}^{+} \bullet \text { free radical scavenging activity }(\%)=\left(\mathrm{A}_{\text {sample }}-\mathrm{A}_{\text {blank }}\right) / \mathrm{A}_{\text {sample }} \times 100 \% \text {. }
$$

\subsection{Selection of Proteolytic Enzyme}

The false abalone hydrolysates produced using five different proteolytic enzymes were subjected to 3.3 and 3.4 to select the best enzyme that produced the highest hydrolysis degree and ABTS ${ }^{+\bullet}$ free radical scavenging activity, which was further used in 3.6 for the optimization of the optimal hydrolysis conditions.

\subsection{Response Surface Methodology}

A three-factor face-centered central composite design (F-CCCD) was applied with hydrolysis temperature $\left({ }^{\circ} \mathrm{C}\right)$, hydrolysis time $(\mathrm{h})$, and hydrolysis $\mathrm{pH}$ as independent variables, and hydrolysis degree (\%) and $\mathrm{ABTS}^{+}{ }^{\bullet}$ free radical scavenging activity (\%) as responses. The three uncoded levels corresponding to the codes $(-1,0,+1)$ of the three independent variables were chosen based on preliminary testing. Using the 17 experimental combinations, the following second-degree polynomial model was fitted (Equation 6):

$$
Y=\beta_{0}+\beta_{1} A+\beta_{2} B+\beta_{3} C+\beta_{11} A^{2}+\beta_{22} B^{2}+\beta_{33} C^{2}+\beta_{12} A B+\beta_{13} A C+\beta_{23} B C
$$

where $\mathrm{Y}$ is the estimated response; $\mathrm{A}, \mathrm{B}, \mathrm{C}$ are independent variables, i.e., hydrolysis temperature, hydrolysis time, and hydrolysis $\mathrm{pH}$, respectively; $\beta_{0}$ is the intercept coefficient; $\beta_{1}, \beta_{2}$, and $\beta_{3}$ are the linear coefficients; $\beta_{11}, \beta_{22}$, and $\beta_{33}$ are the quadratic coefficients; and $\beta_{12}, \beta_{13}, \beta_{23}$ are the linear by linear interaction coefficients. The model includes linear, quadratic, and interaction coefficients.

\subsection{Fractionation of the Optimized Hydrolysates}

The optimized hydrolysates produced at the optimal conditions were fractionated using a polyethersulphone (PES) ultrafiltration membrane (Millipore Co., USA) with a MWCO of 10, 5, and $3 \mathrm{kDa}$. Four fractions were obtained with a MW of $<3,3-5,5-10$, and $>10 \mathrm{kDa}$. These fractions were analyzed for $\mathrm{ABTS}^{+} \bullet$ free radical scavenging activity, and the fraction with the highest activity was subjected to 3.8 .

\subsection{LC-MS/MS Assay}

The peptide sequences in the hydrolysate fraction were identified using LC-MS/MS. The LC system was equipped with an RP-C18 column (125 mm $\times 3 \mathrm{~mm}$, particle size $5 \mu \mathrm{m}$, Guangzhou FLM Scientific Instrument Co., Ltd., Guangzhou, China), and was operated with mobile phases: solvent A $(0.1 \%(\mathrm{v} / \mathrm{v})$ formic acid in water) and solvent B (acetonitrile supplemented with $0.1 \%(\mathrm{v} / \mathrm{v})$ formic acid). The column was equilibrated with $95 \%$ solvent A. Samples were loaded from the autosampler into the column and then separated with gradient conditions (B\%): 0-30 $\min 4-50 \%$, 30-34 $\min 50-100 \%$, and $34-35 \mathrm{~min} 100 \%$. The MS/MS analysis was performed in quadruple using an Orbitrap mass spectrometer (Q Exactive mass spectrometer, Thermo Fisher Scientific Co., Bremen, Germany). Full scan spectra were acquired over m/z 350-2000 and 10 MS2 scans were selected. The software packages of Mascot 2.2 and Uniprot database were used to process and analyze the data.

\subsection{Molecular Docking}

The molecular docking studies were based on the crystal structure of the human MPO (PDB ID: 3F9P) at a resolution of $2.93 \AA$ [37]. The molecular mechanism of peptide interaction with MPO was performed using advanced molecular docking software, Discovery Studio 2017R2 (Accelrys, San Diego, 
CA, USA) by the CDOCKER model. During the algorithm, the receptor is set as rigid while the peptides (ligands) can be flexible. The "Receptor-Ligand Interactions" performance parameters were set as: (i) Top hits-10, Pose cluster radius-0.5; (ii) Random conformations-10, Dynamics steps-1000, Dynamics target temperature-1000, Include electrostatic interactions-True; (iii) Orientations to refine-10, Maximum bad orientations-800, Orientation vdW energy threshold-300; (iv) Simulated annealing-True, Heating steps-2000, Heating target temperature-700, Cooling steps-5000, Cooling target temperature-300; (v) Forcefield-CHARMm (Chemistry at HARvard Macromolecular Mechanics), Use full potential-False, Ligand partial charge method-Momany-Rone, Final minimization - full potential, Final minimization gradient tolerance -0 , Final minimization gradient tolerance-0, Prepare input receptor-True, Grid extension-8.0, Random number seed-314159; (vi) Parallel processing-True, Batch size-1.

Before docking, the MPO structure was treated with the Prepare Protein program in Discovery Studio to build loops, minimize the energy, and protonize and remove water molecules. As shown in Figure 5, the docking pocket was defined based on the active sites of MPO described previously, and the human lactoferrin-derived peptide hLF1-11 was used as the reference peptide [10]. Prior to the docking, the identified 193 peptides were minimized in energy using the following parameters: (i) Algorithm-Smart minimizer, Max steps—200, RMS gradient-0.1, Energy change-0, Save results frequency-0; (ii) Nonbond list radius-14, Nonbond higher cutoff distance-12, Nonbond lower cutoff distance-10; (iii) Electrostatics-Automatic.

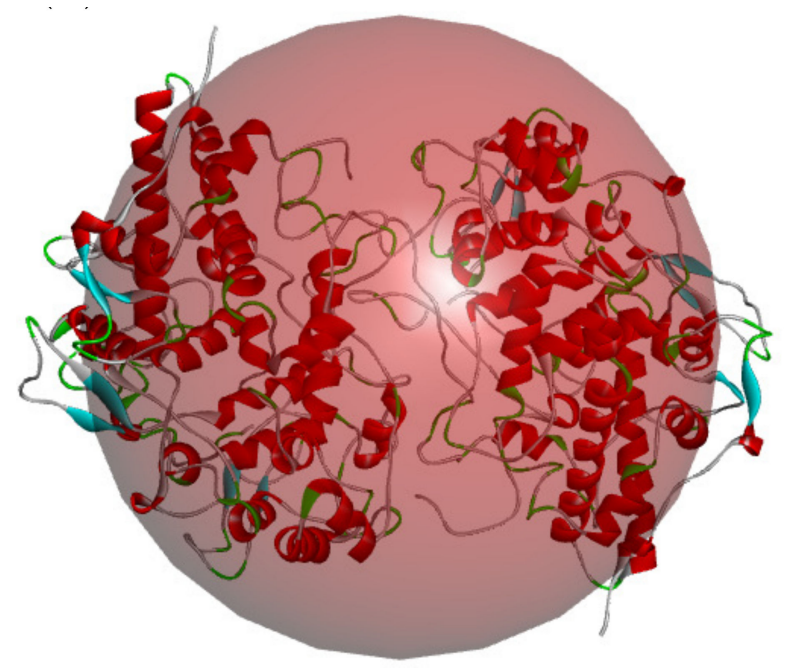

Figure 5. The docking pocket of human MPO (PDB ID: 3F9P).

\subsection{Statistical Analysis}

Design Expert version 8.0 (Stat-Ease Inc., Minneapolis, MN, USA) was used to perform surface response analysis, including the ANOVA decomposition and significance tests for model coefficients, the optimization of the response as a function of the independent variables, and the plotting of the fitted surface. Triplicates were performed, and the results were given as mean $\pm \mathrm{SD}$. The significance was analyzed using SPSS 11.5 (SPSS Inc, Chicago, IL, USA) with a significance level of $p<0.01$.

\section{Conclusions}

The false abalone hydrolysates produced from proteolytic enzymes have antioxidant properties. Trypsin was found to produce hydrolysates with the highest hydrolysis degree and the highest $\mathrm{ABTS}^{+}$free radical scavenging activity than other proteases such as pepsin, alcalase, neutrase, and flavourzyme. The optimization of the use of trypsin to produce hydrolysates was of practical importance. Hydrolysate fractions with lower MW showed higher $\mathrm{ABTS}^{+\bullet}$ free radical scavenging activity, and 193 peptide sequences were characterized using the LC-MS/MS. There were 133 peptides 
successfully docked onto the MPO enzyme and 107 of them were characterized with interactions. Peptide no. 39, with amino acid sequence of DTETGVPT, showed the highest consensus score, and its structure as well as the molecular interactions with the amino acid residues in active sites of MPO were similar to a previously characterized peptide hLF1-11. The predicted interactions between peptide no. 39 and MPO included charge interactions, hydrogen bonds, and covalent bonds, which suggested peptide no. 39 might be a potential inhibitor for MPO. Thus, our findings suggested the peptides in the produced antioxidative hydrolysate may exert antioxidant activity in vivo, which have application potential in the development of pharmaceuticals and functional foods.

Supplementary Materials: The following are available online at http:/ / www.mdpi.com/1660-3397/17/2/116/s1, Table S1: The peptide sequences characterized in hydrolysate fraction of $\mathrm{MW}<3 \mathrm{kDa}$.

Author Contributions: S.H., M.D., H.S., and B.Z. conceived and designed the study, S.H., J.Q., M.T. and X.S. performed the experiments, S.H., Y.Z., and J.Q. analyzed the data. Y.Z. and S.H. wrote and edited the paper.

Funding: This research was funded by the National Natural Science Foundation of China (no. 31701524), the Anhui Provincial Natural Science Foundation (no. 1708085MC70), the Fundamental Research Funds for the Central Universities (no. JZ2018HGTB0245), and the Financial Grant from the China Postdoctoral Science Foundation (no. 2017M611208, no. 2018T110211). The APC was funded by the Financial Grant from the China Postdoctoral Science Foundation.

Acknowledgments: The authors wish to thank the anonymous reviewers for their constructive comments and the editor for his review of the manuscript. The authors also gratefully acknowledge the assistance of Dr. An'guo Sun, Shanghai Hoogen Biotechnology Co., Ltd., Shanghai, China, in the LC-MS/MS experiments, and the assistance of Dr. Hui Chen, School of Food Science and Technology, National Engineering Research Center of Seafood, Dalian Polytechnic University, in the molecular docking analysis.

Conflicts of Interest: The authors declare no conflict of interest.

\section{References}

1. Sun, M.L.; Zhang, Q.; Ma, Q.; Fu, Y.-H.; Jin, W.G.; Zhu, B.-W. Affinity purification of angiotensin-converting enzyme inhibitory peptides from Volutharpa ampullacea perryi protein hydrolysate using Zn-SBA-15 immobilized ACE. Eur. Food Res. Technol. 2018, 244, 457-468. [CrossRef]

2. He, S.; Sun, X.; Du, M.; Chen, H.; Tan, M.; Sun, H.; Zhu, B. Effects of muscle protein denaturation and water distribution on the quality of false abalone (Volutharpa ampullacea perryi) during wet heating. J. Food Process Eng. 2018, e12932. [CrossRef]

3. Wang, H.; Zhao, J.; Li, D.; Wen, C.; Liu, H.; Song, S.; Zhu, B. Comparison of polysaccharides of Haliotis discus hannai and Volutharpa ampullacea perryi by PMP-HPLC-MSn analysis upon acid hydrolysis. Carbohyd. Res. 2015, 415, 48-53. [CrossRef] [PubMed]

4. Sila, A.; Bougatef, A. Antioxidant peptides from marine by-products: Isolation, identification and application in food systems. A review. J. Funct. Foods 2016, 21, 10-26. [CrossRef]

5. Gómez-Guillén, M.; Giménez, B.; López-Caballero, M.A.; Montero, M. Functional and bioactive properties of collagen and gelatin from alternative sources: A review. Food Hydrocolloid. 2011, 25, 1813-1827. [CrossRef]

6. Sarmadi, B.H.; Ismail, A. Antioxidative peptides from food proteins: A review. Peptides 2010, 31, 1949-1956. [CrossRef]

7. Kim, S.K.; Wijesekara, I. Development and biological activities of marine-derived bioactive peptides: A review. J. Funct. Foods 2010, 2, 1-9. [CrossRef]

8. Malle, E.; Furtmüller, P.; Sattler, W.; Obinger, C. Myeloperoxidase: A target for new drug development? Br. J. Pharmacol. 2007, 152, 838-854.

9. Guerra-Vargas, M.A.; Rosales-Hernández, M.C.; Martínez-Fonseca, N.; Padilla-Martínez, I.; Fonseca-Sabater, Y.; Martínez-Ramos, F. 2-Acetyl-4-aminoresorcinol derivatives: synthesis, antioxidant activity and molecular docking studies. Med. Chem. Res. 2018, 27, 1186-1197. [CrossRef]

10. Van der Does, A.M.; Hensbergen, P.J.; Bogaards, S.J.; Cansoy, M.; Deelder, A.M.; van Leeuwen, H.C.; Drijfhout, J.W.; van Dissel, J.T.; Nibbering, P.H. The human lactoferrin-derived peptide hLF1-11 exerts immunomodulatory effects by specific inhibition of myeloperoxidase activity. J. Immunol. 2012, 1102777. [CrossRef] 
11. Tavano, O.L. Protein hydrolysis using proteases: An important tool for food biotechnology. J. Mol. Catal. B: Enzym. 2013, 90, 1-11. [CrossRef]

12. Hou, H.; Li, B.; Zhao, X.; Zhang, Z.; Li, P. Optimization of enzymatic hydrolysis of Alaska pollock frame for preparing protein hydrolysates with low-bitterness. LWT-Food Sci. Technol. 2011, 44, 421-428. [CrossRef]

13. Mao, X.Y.; Cheng, X.; Wang, X.; Wu, S.J. Free-radical-scavenging and anti-inflammatory effect of yak milk casein before and after enzymatic hydrolysis. Food Chem. 2011, 126, 484-490. [CrossRef]

14. Kong, B.; Xiong, Y.L. Antioxidant activity of zein hydrolysates in a liposome system and the possible mode of action. J. Agric. Food Chem. 2006, 54, 6059-6068. [CrossRef] [PubMed]

15. Chen, C.; Chi, Y.J.; Zhao, M.Y.; Xu, W. Influence of degree of hydrolysis on functional properties, antioxidant and ACE inhibitory activities of egg white protein hydrolysate. Food Sci. Biotechnol. 2012, 21, 27-34. [CrossRef]

16. Ovissipour, M.; Kenari, A.A.; Motamedzadegan, A.; Nazari, R.M. Optimization of enzymatic hydrolysis of visceral waste proteins of yellowfin tuna (Thunnus albacares). Food Bioprocess Tech. 2012, 5, 696-705. [CrossRef]

17. Cheison, S.C.; Schmitt, M.; Leeb, E.; Letzel, T.; Kulozik, U. Influence of temperature and degree of hydrolysis on the peptide composition of trypsin hydrolysates of $\beta$-lactoglobulin: Analysis by LC-ESI-TOF/MS. Food Chem. 2010, 121, 457-467. [CrossRef]

18. You, L.; Regenstein, J.M.; Liu, R.H. Optimization of hydrolysis conditions for the production of antioxidant peptides from fish gelatin using response surface methodology. J. Food Sci. 2010, 75, C582-C587. [CrossRef] [PubMed]

19. Ajibola, C.F.; Fashakin, J.B.; Fagbemi, T.N.; Aluko, R.E. Effect of peptide size on antioxidant properties of African yam bean seed (Sphenostylis stenocarpa) protein hydrolysate fractions. Int. J. Mol. Sci. 2011, 12, 6685-6702. [CrossRef] [PubMed]

20. Ko, J.Y.; Lee, J.H.; Samarakoon, K.; Kim, J.S.; Jeon, Y.J. Purification and determination of two novel antioxidant peptides from flounder fish (Paralichthys olivaceus) using digestive proteases. Food Chem. Toxicol. 2013, 52, 113-120. [CrossRef]

21. Chen, M.; Li, B. The effect of molecular weights on the survivability of casein-derived antioxidant peptides after the simulated gastrointestinal digestion. Innov. Food Sci. Emerg. 2012, 16, 341-348. [CrossRef]

22. Wang, B.; Li, L.; Chi, C.F.; Ma, J.H.; Luo, H.Y.; Xu, Y.f. Purification and characterisation of a novel antioxidant peptide derived from blue mussel (Mytilus edulis) protein hydrolysate. Food Chem. 2013, 138, 1713-1719. [CrossRef] [PubMed]

23. Najafian, L.; Babji, A.S. Production of bioactive peptides using enzymatic hydrolysis and identification antioxidative peptides from patin (Pangasius sutchi) sarcoplasmic protein hydolysate. J. Funct. Foods 2014, 9, 280-289. [CrossRef]

24. Ngoh, Y.Y.; Gan, C.Y. Enzyme-assisted extraction and identification of antioxidative and $\alpha$-amylase inhibitory peptides from Pinto beans (Phaseolus vulgaris cv. Pinto). Food Chem. 2016, 190, 331-337. [CrossRef] [PubMed]

25. Guo, H.; Kouzuma, Y.; Yonekura, M. Structures and properties of antioxidative peptides derived from royal jelly protein. Food Chem. 2009, 113, 238-245. [CrossRef]

26. Memarpoor-Yazdi, M.; Asoodeh, A.; Chamani, J. A novel antioxidant and antimicrobial peptide from hen egg white lysozyme hydrolysates. J. Funct. Foods 2012, 4, 278-286. [CrossRef]

27. Mendis, E.; Rajapakse, N.; Kim, S.K. Antioxidant properties of a radical-scavenging peptide purified from enzymatically prepared fish skin gelatin hydrolysate. J. Agric. Food Chem. 2005, 53, 581-587. [CrossRef]

28. Chen, H.M.; Muramoto, K.; Yamauchi, F. Structural analysis of antioxidative peptides from Soybean. beta.-Conglycinin. J. Agric. Food Chem. 1995, 43, 574-578. [CrossRef]

29. Mendis, E.; Rajapakse, N.; Byun, H.G.; Kim, S.K. Investigation of jumbo squid (Dosidicus gigas) skin gelatin peptides for their in vitro antioxidant effects. Life Sci. 2005, 77, 2166-2178. [CrossRef]

30. Shazly, A.B.; He, Z.; El-Aziz, M.A.; Zeng, M.; Zhang, S.; Qin, F.; Chen, J. Fractionation and identification of novel antioxidant peptides from buffalo and bovine casein hydrolysates. Food Chem. 2017, 232, 753-762. [CrossRef]

31. Zhuang, H.; Tang, N.; Yuan, Y. Purification and identification of antioxidant peptides from corn gluten meal. J. Funct. Foods 2013, 5, 1810-1821. [CrossRef]

32. Taheri, A.; Farvin, K.S.; Jacobsen, C.; Baron, C.P. Antioxidant activities and functional properties of protein and peptide fractions isolated from salted herring brine. Food Chem. 2014, 142, 318-326. [CrossRef] [PubMed] 
33. Hunter, H.N.; Demcoe, A.R.; Jenssen, H.; Gutteberg, T.J.; Vogel, H.J. Human lactoferricin is partially folded in aqueous solution and is better stabilized in a membrane mimetic solvent. Antimicrob. Agents Ch. 2005, 49, 3387-3395. [CrossRef] [PubMed]

34. Battistuzzi, G.; Bellei, M.; Zederbauer, M.; Furtmüller, P.G.; Sola, M.; Obinger, C. Redox thermodynamics of the Fe (III)/Fe (II) couple of human myeloperoxidase in its high-spin and low-spin forms. Biochemistry 2006, 45, 12750-12755. [CrossRef] [PubMed]

35. Fiedler, T.J.; Davey, C.A.; Fenna, R.E. X-ray crystal structure and characterization of halide-binding sites of human myeloperoxidase at $1.8 \AA$ resolution. J. Biol. Chem. 2000, 275, 11964-11971. [CrossRef] [PubMed]

36. Li, H.B.; Wong, C.C.; Cheng, K.W.; Chen, F. Antioxidant properties in vitro and total phenolic contents in methanol extracts from medicinal plants. LWT Food Sci. Technol. 2008, 41, 385-390. [CrossRef]

37. Carpena, X.; Vidossich, P.; Schroettner, K.; Callisto, B.M.; Banerjee, S.; Stampler, J.; Soudi, M.; Furtmüller, PG.; Rovira, C.; Fita, I. Essential role of proximal histidine-asparagine interaction in mammalian peroxidases. J. Biol. Chem. 2009, 284, 25929-25937. [CrossRef]

(C) 2019 by the authors. Licensee MDPI, Basel, Switzerland. This article is an open access article distributed under the terms and conditions of the Creative Commons Attribution (CC BY) license (http://creativecommons.org/licenses/by/4.0/). 